\title{
Relações solo-fauna durante sucessão florestal em áreas de clareiras por movimento de massa em Mata Atlântica
}

\author{
Soil and Fauna relationships during landslide scar recovering in Atlantic Forest \\ CHIROL $^{1}$, A. A.; COELHO NETTO ${ }^{2}$, A. L.; PEREZ ${ }^{3}$, D. V \\ achilles.chirol@uerj.br;
}

\section{Resumo}

Os movimentos de massa são feições naturais do Ambiente de Mata Atlântica, trazendo diversas transformações na paisagem, tanto do ponto de vista ecológico como hidrológico. $\mathrm{O}$ presente trabalho observou como se dá a recuperação dos nutrientes do solo e da fauna de microartrópodes em três áreas de deslizamento, levando em conta as características morfológicas de cada uma, que variam em tamanho e forma, sempre as comparando com uma área de floresta clímax local. Observou-se que as clareiras de maior porte apresentam condições menos favoráveis a sucessão, assim como maior propagação de efeito de borda. A densidade da fauna diferiu sensivelmente entre as áreas de clareira e a da floresta, assim como os principais nutrientes do solo, com maiores teores na floresta e no topo do solo, principalmente o fósforo. A diversidade de habitats que são criados por estas clareiras pode estar fortemente associada à biodiversidade elevada típica destes ecossistemas, influenciando diretamente na sua dinâmica na resiliência deste.

Palavras-chave: Sucessão Florestal, Movimentos de Massa, Mata Atlântica

\begin{abstract}
Landslides are natural features of the Atlantic rainforest environment, causing various changes to the landscape, both from ecological and hydrological viewpoints. This paper observed how the nutrients in the soil and the microarthropod fauna recovered in three landslide areas, taking into account the morphological characteristics of each, which vary in size and shape, always comparing them to an area of local climax forest. It was found that the larger gaps show conditions less favourable to succession, and a greater spread of border effect. The fauna density differed considerably between the landslide and forest areas, as did the main soil nutrients, with larger contents in the forest and topsoil, chiefly phosphorus. The diversity of habitats created by these glades can be closely associated with the typical high biodiversity of these ecosystems, directly influencing their dynamics in their resilience.
\end{abstract}

Keywords: Forest sucession, Landslides, Atlantic Forest

\footnotetext{
${ }^{l}$ Achiles d'Avila Chirol, Deparatmento de Geografia Física, Universidade do Estado do Rio de Janeiro, Brasil.

${ }^{2}$ Ana Luiza Coelho Netto, Departamento de Geografia/Laboratório de Geo-hidroecologia, Universidade Federal do Rio de Janeiro, Brasil.
} 


\section{INTRODUÇÃO}

As clareiras geradas por deslizamentos em encostas íngremes e florestadas fazem parte da dinâmica evolutiva de áreas montanhosas de regiões úmidas tropicais ou extra-tropicais. Estes processos são detonados, geralmente, por eventos de chuvas extremas e sua dimensão espacial resulta da interação de diversas variáveis-controle locais, o que faz com que estas clareiras apresentem tamanhos e formas variáveis e diferentes condições de solo remanescente. Coelho Netto et al (2007) destacam como estas feições são importantes na evolução geomorfológica e funcionam como vetores de transformações da Paisagem nas encostas recobertas por Mata Atlântica. A consequiência direta dessas cicatrizes erosivas é a destruição do sistema de relações solo-biota e a propagação de efeitos de borda para a floresta adjacente. Denslow (1987) ressalta que clareiras são próprias da dinâmica dos ecossistemas florestais, o que permite a manutenção da biodiversidade.

Diante deste quadro, abre-se uma questão: até que ponto o ambiente florestal consegue ser resiliente as clareiras de deslizamentos? Apesar da extensa literatura sobre clareiras por deslizamento, tanto do ponto de vista hidrológico quanto funcional dos seus condicionantes (Guariguata et al, 1990, Zarin et al, 1995, Larsen et al, 1999, Glade, 2003, Fernandes et al, 2004, Lin et al, 2005, Alcântara et al, 2006, Geertsema et al, 2007, Clark et al 2016 e Neto et al. 2017) pouco é discutido sobre o papel do tamanho e forma da clareira durante a sucessão, e menos ainda quando se fala do efeito de borda que é propagado para a floresta adjacente. Mas destaca-se que o topo do solo tem um papel fundamental dentro da sucessão, por ser o compartimento onde ocorre a decomposição e os principais processos hidrológicos em bacias de Mata Atlântica (Coelho Netto, 1987)

No contexto da interação solo-fauna destaca-se ainda a ciclagem de nutrientes como efeito terminal: a matéria orgânica e as propriedades químicas influenciam na capacidade de troca catiônica e no processo de estruturação do solo; por conseguinte, influencia e é influenciado pelo comportamento da água no solo, assim como pela transferência de nutrientes para as plantas. Em relação ao efeito que estas clareiras por deslizamento tem para os nutrientes do solo em áreas tropicais, WILCKE et al (2003) aponta na literatura a seguinte discussão: alguns trabalhos afirmam que ocorre uma diminuição na concentração destes, pela perda do topo do solo, enquanto outros afirmam que com a perda dos horizontes superficiais, camadas menos intemperizadas afloram, aumentando assim a concentração de nutrientes. Zarin et al (1995) observaram que existe uma lenta recuperação dos nutrientes em clareiras, que dependendo do nutriente, pode ser da ordem de mais de 100 anos. E Restrepo et al (2003) observam que cerca de 53 ton/ha de biomassa podem ser 
perdidos por século através de deslizamentos, podendo afetar inclusive o estoque de carbono regional. Sylvain ET AL (2014) e Chen at al (2017) ainda destacam que alterações climáticas em escala global podem gerar alterações nas taxas de sequestro de carbono global.

Assim sendo, busca-se neste estudo conhecer a distribuição espacial de algumas propriedades químicas do topo solo (carbono, nitrogênio, fósforo e potássio) em associação ao estudo quantitativo dos microartrópodes ao longo do processo sucessional, comparando-se clareiras de cada uma das classes definidas por Vilella (1999) em comparação a uma área de floresta clímax. Local e as bordas adjacentes às clareiras. Todas as clareiras foram originadas no mesmo período (fevereiro de 1988) e estão localizadas em áreas de floresta secundária tardia ou climácica.

\section{METODOLOGIA}

O plano amostral levou em consideração a área controle e dividiu as clareiras em 4 domínios: a alta encosta, a média encosta, a borda direita e a borda esquerda, perfazendo um total de 13 áreas. Nestas foram coletadas amostras de fauna e solo para fins de comparação entre estas. A opção pelas coletas nas áreas de alta e média encosta, chamados aqui de domínios 1 e 2 respectivamente, dentro das clareiras se deveu a estas serem as áreas de sucessão mais complexa, em função da dinâmica hidro-erosiva, como já foi identificado por Guariguata et al (1990). As áreas de borda foram escolhidas para pode se ter uma idéia da propagação de efeitos degenerativos para a floresta adjacente. As amostras foram coletadas no período de junho de 2008. As áreas de borda foram escolhidas para pode se ter uma idéia da propagação de efeitos degenerativos para a floresta adjacente, já que estes efeitos já foram identificados por outros trabalhos em áreas de clareira (Montezuma 2005, Chirol et al, 2007), mas sem relacionar a intensidade deste efeito com o tamanho e forma da clareira.

O levantamento da estrutura da vegetação foi feito a partir de parcelas de $50 \mathrm{~m} 2$ de área $(5 \mathrm{~m}$ x 10m). Este tamanho de parcela foi escolhido de acordo com o proposto por De Vuono (2002) coloca que para áreas sob sucessão inicial são parcelas pequenas são recomendadas.nTambém por conta do estágio sucessional das áreas de deslizamento, adotou-se como critério de inclusão o PAP (perímetro a altura do peito) a 1,30m igual ou superior a 5,0cm $(\mathrm{DAP}=1,5)$. Também foi medida a altura de cada indivíduo, a partir da observação de três observadores. A partir dos dados foram medidos o DAP (diâmetro a altura do peito), com a fórmula DAP = PAP/ $\pi$. 
A amostragem da fauna deu-se a partir da coleta de solo e serrapilheira com um anel de $5 \mathrm{~cm}$ de diâmetro e 5 de profundidade; posteriormente foi transferida para tubos de PVC de $15 \mathrm{~cm}$ de altura, com tela de $5 \mathrm{~mm}$ no fundo. Ainda em campo as amostras foram separadas nas camadas de serrapilheira recém caídas (O1) e parcialmente decompostas $(\mathrm{O} 2)$ e de solo de $0-5 \mathrm{~cm}$ e de $5-10 \mathrm{~cm}$. Em função da rápida decomposição e incorporação do material húmico ao solo, não houve como coletar separadamente a camada $\mathrm{H}$.

Em laboratório as amostras de fauna foram processadas no extrator do tipo Berlese, sem luz e sob temperatura ambiente durante dez dias para triagem da fauna. Após este prodedimento, a fauna foi identificada e quantificada com auxílio de lupa binocular (modelo Zveiss 6).

As análises de laboratório de solo seguiram o método da EMBRAPA (1997) para as análises químicas (nitrogênio, carbono, fósforo, potássio, alumínio, pH). Foram coletadas amostras nas profundidades de $0-5 \mathrm{~cm}, 5-10 \mathrm{~cm}, 10-20 \mathrm{~cm}$ e $20-40 \mathrm{~cm}$ com o auxílio de um trado sonda. Os dados foram tratados estatisticamente, com a aplicação dos testes ANOVA, quando as amostras possuíam distribuição normal dos dados e Kruskal-Wallis quando está não se encontrava normal. Para agrupar os dados foram utilizados os testes de Scheffè (paramétrico) e de Dunn (não paramétrico).

\section{1 Área de Estudo}

As áreas de estudo situam-se no maciço da Tijuca, localizado no município do Rio de Janeiro, com uma área total de $118.7 \mathrm{Km} 2$ (11.870 ha) considerando a curva de nível contínua na cota de 40m (a.n.m.) como limite externo, se trata de uma das três unidades fisiográficas montanhosas da cidade do Rio de Janeiro (complementado pelos maciços da Pedra Branca e Mendanha) (figura 1). Este maciço tem suas encostas recoberta por vegetação, na maioria resultado de um avançado processo natural de regeneração, não excluindo a influência de replantios iniciados no século XIX de espécies nativas e exóticas para a recuperação desta paisagem.

Podemos considerar que o substrato rochoso do Maciço da Tijuca data do Pré-Cambriano, e faz parte da grande faixa móvel que formou as rochas do Sudeste brasileiro, como consequiência das falhas tectônicas do Terciário inferior. É formado essencialmente de gnaisses, principalmente gnaisse facoidal e biotita gnaisse, com manchas isoladas de granitos em sua porção Leste (Costa, 1986). 
O clima do Maciço da Tijuca segundo a classificação de Koppen é tropical de altitude (Cf) com temperaturas variando de valores médios máximos em $25^{\circ} \mathrm{C}$ em fevereiro e mínimo de $19^{\circ} \mathrm{C}$ em junho, resultando em uma média anual de $22^{\circ} \mathrm{C}$. A temperatura máxima pode atingir $35^{\circ} \mathrm{C}$ durante o verão e o mínimo excedendo $10^{\circ} \mathrm{C}$ durante o período de inverno. A precipitação anual média oscila entre 2.000 e $2.500 \mathrm{~mm}$, podendo atingir picos de $3.300 \mathrm{~mm}$ em anos muito chuvosos e picos negativos de $1.600 \mathrm{~mm}$ em anos mais secos. A maior parte das chuvas se concentra nos 4 primeiros meses dos anos. A maior pluviosidade que ocorre no verão é uma resposta direta ao impacto causado pela frente polar Atlântica, alterando a dinâmica habitual da atmosfera (Coelho Netto, 1985).

De acordo com Coelho Netto et al (2007), a área encontra-se inserida na metrópole do Rio de Janeiro, sofrendo assim interferência direta da pressões e dos vetores de transformação da cidade.

\section{2 Área laboratório 1: a clareira da Vista do Almirante}

A origem da cicatriz erosiva em estudo está relacionada aos "inputs" extremos ocorridos nas chuvas de grandes magnitudes e intensidades de fevereiro de 1988 (954,4 mm). Neste mesmo ano foram registradas chuvas contínuas de 2 a 23 de fevereiro com 3 episódios de chuvas intensas nos dias 3, 12 e 20, concentrando chuvas que variaram de 10 a $16 \%$ da pluviosidade média anual, sendo que o episódio do dia 20 foi o desencadeador de deslizamentos de encostas generalizados (Brandão 1994). As fortes chuvas dessa ocasião acabaram por gerar a construção do Mirante da Vista do Almirante, área da cicatriz em questão.

A área piloto apresenta solos coluvio-residuais na porção superior e depósitos recentes na inferior, local da deposição do material do deslizamento. Na porção superior, os solos rasos, associados à morfologia das encostas, impedem um maior acúmulo de umidade, tornando lenta a recolonização. Já na porção inferior a recolonização se deu de forma mais rápida, graças a uma menor declividade que permitiu um maior acúmulo de matéria orgânica, associada aos detritos orgânicos carreados no movimento e solos mais profundos. Entre essas duas áreas existe um afloramento de rocha alterada no fundo da ravina, e esta desestabiliza o substrato dificultando assim a recolonização. (Rocha Leão, 1997). 


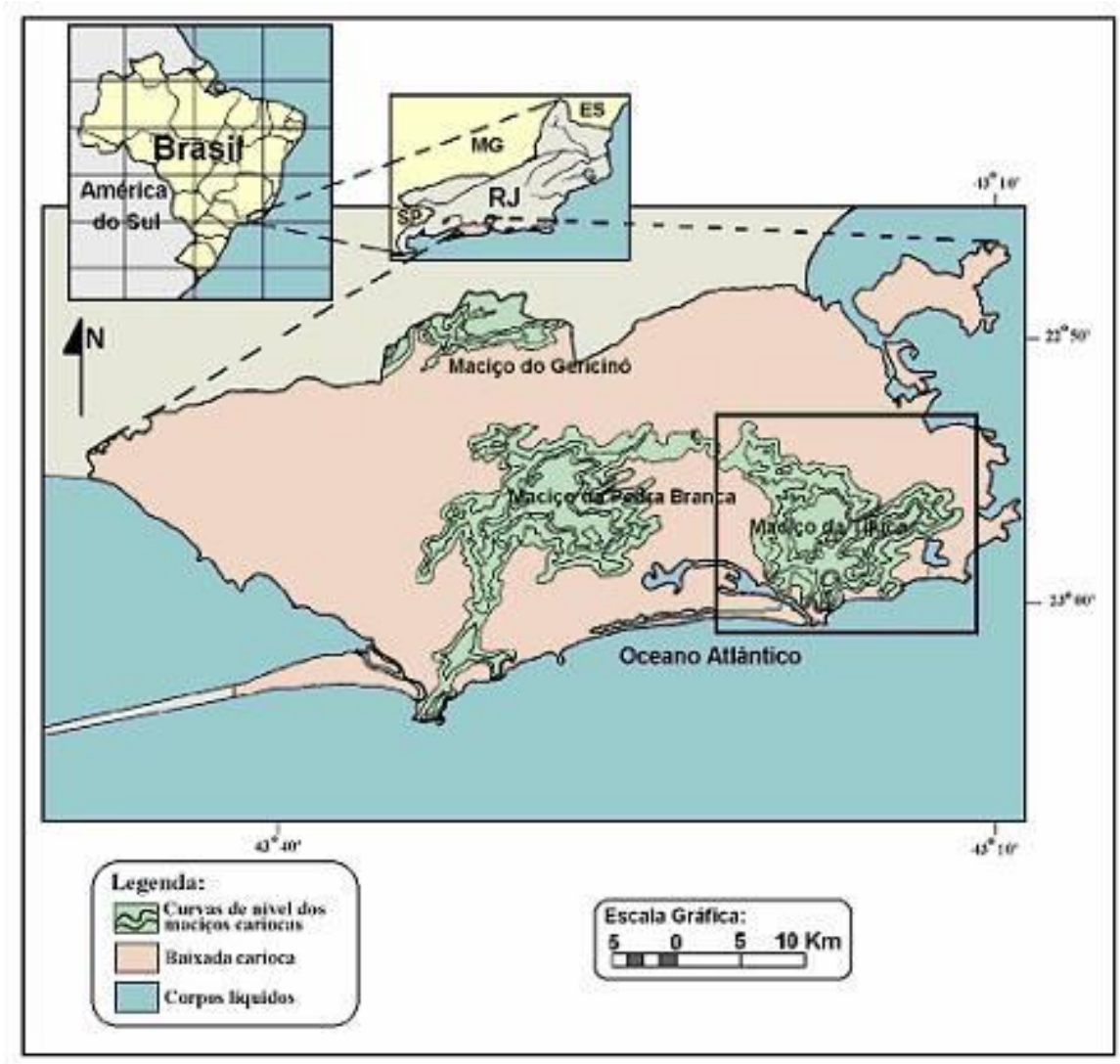

Figura 1: Mapa de localização do Maciço da Tijuca. Fonte: GEOHECO/UFRJ.

A pequena largura da cicatriz $(0,6 \mathrm{ha})$ permitiu o recobrimento da mesma por espécies pioneiras e secundárias iniciais em toda a sua extensão. O processo de revegetação desigual se dá a partir de aspectos da própria morfologia da clareira. O entorno é constituído por uma mata secundária tardia em estado avançado de regeneração com sub-bosque dominado por palmito (Euterpe edulis).

\section{3 Área laboratório 2: a cicatriz da Vista Chinesa}

A clareira formada pelo evento erosivo de 1988 está inserida no setor B do Parque Nacional da Tijuca. Esta tem uma área toral de 1,8 ha, estando o seu topo localizado na base da estrada, próximo ao divisor da bacia e a sua base situa-se no fundo de vale de um canal de primeira ordem tributário do rio dos Macacos. Este deslizamento apresentou grande volume de solo mobilizado, com cerca de $12.480 \mathrm{~m}^{3}$ e com profundidade média variando de 1,3 a 1,5m. (Silva Filho, 1992).

Rocha Leão (1997) observou três domínios morfológicos bem definidos, que refletem as diferentes posições na encosta São eles: (a) Alta-Encosta: É a porção superior da cicatriz, que se estende desde a estrada até a primeira ruptura de declive. Constitui um trecho de alta declividade, com solos expostos, evidências de fluxos superficiais e uma pequena rede de ravinamentos de 
drenagem efêmer, onde houve uma tentativa de recuperação pela introdução de bambu. (b) A Média-Encosta: É a porção central da cicatriz, que se estende desde a primeira até a segunda ruptura de declive. Constituí também o trecho de maior gradiente e atividade erosiva, possuindo afloramentos de rocha alterada e sã na transição com o domínio de baixa-encosta. Negreiros et al (2009) observaram que há uma carga de sedimentos da ordem de 1,03 ton/ha ao ano neste domínio; (c) Baixa-Encosta: É a base da cicatriz, que se estende desde a segunda ruptura de declive do perfil até o canal fluvial. Constitui-se no trecho onde ocorreu a deposição do material mobilizado no deslizamento. Formada por um extenso pacote de solo, com uma grande ravina no meio, esta área apresenta revegetação espontânea acelerada, com formação de dossel contínuo e acúmulo de serrapilheira.

\section{4 Área Laboratório 3: a cicatriz do Gabião:}

Esta cicatriz-clareira também está associada aos eventos de fevereiro de 1988, e em parte reproduz a morfologia da cicatriz-clareira da Vista Chinesa, porém com um tamanho menor (1,2 ha). Rocha Leão (1997) identificou 3 domínios morfológicos, que são: 1 - A porção superior, de declividade acentuada e sem feições côncavas, o que dificulta o ravinamento; 2 - A porção central, caracterizada pela presença de um segmento de encosta extremamente íngreme, com solos expostos, formação de crostas e superfícies seladas; 3 - Zona abaixo da segunda ruptura do declive, com menores declividades e onde o material do deslizamento se depositou.

\section{5 Área controle: Mata do pai Ricardo}

Esta área foi escolhida como controle no estudo. No interior da bacia encontra-se um trecho de floresta bem conservada, chamada mata do Pai Ricardo onde resiste um fragmento de mata primária com cerca de 200 ha de mata. Neste mesmo trecho de floresta foi conduzido um levantamento de estrutura da vegetação, onde aponta uma predominância de árvores de grande porte, características desse ambiente com áreas basais de 36,62m2/ha no ambiente de encosta, observado por BASILE (2004) em um estudo de reconhecimento da arquitetura do sistema radicular de indivíduos arbóreos e de $97.3 \mathrm{~m} 2 /$ ha no fundo de vale, em estudo conduzido pelo GEOHECOUFRJ/SMAC-RJ (2000). 


\section{RESULTADOS}

\subsection{Estrutura da vegetação}

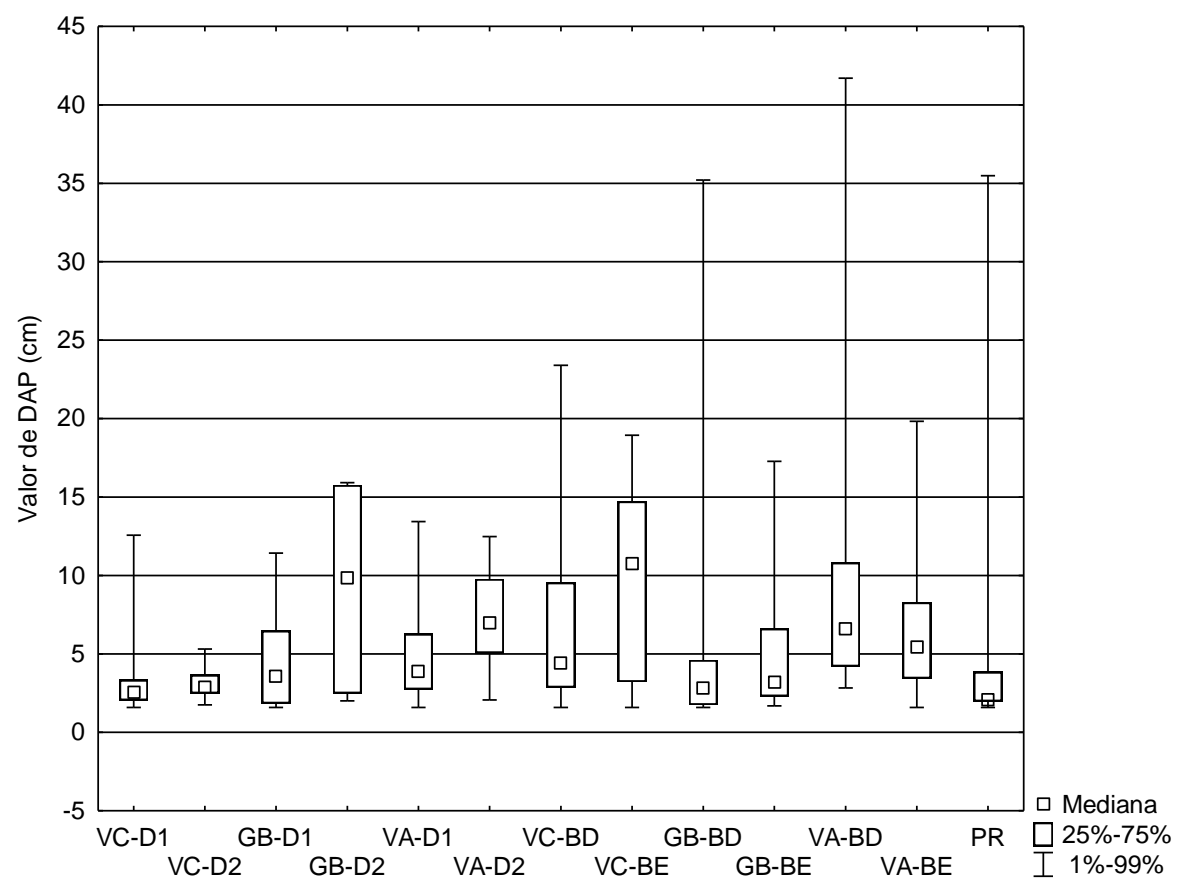

Figura 2: Distribuição da área basal nas áreas de estudo VA - Vista do Almirante; VC - Vista Chinesa; GB - Gabião; PR - Pai Ricardo; D1 - Domínio 1; D2 - Domínio 2, BD- Borda direita; BE - Borda Esquerda. Fonte: Acervo do Autor.

A figura 2 nos mostra a distribuição do DAP nas áreas observadas. De acordo com Guariguata et al (2001), a área do pai Ricardo apresenta o padrão que seria esperado em uma área de clímax local, com a presença de árvores de maior porte, mas com a dominância de indivíduos de menor porte. As bordas direita do Almirante e Gabião apresentam o padrão mais próximo da área controle, apesar da Vista do Almirante não apresentar árvores com DAP inferior a 2,5. De maneira geral, como seria esperado, as áreas das clareiras apresentam indivíduos de menor porte, já que os de maior porte estão ausentes, como seria esperado pelo estágio sucessional em que se encontram. Chama a atenção a baixa área basal no domínio 2 da Vista Chinesa, onde predominam gramíneas e quaresmeiras (melastomataceae), e do domínio 2 do Gabião, onde predominam pteridófitas do gênero gleichenea e algumas espécies pioneiras, como a embaúba (cecrópia). 


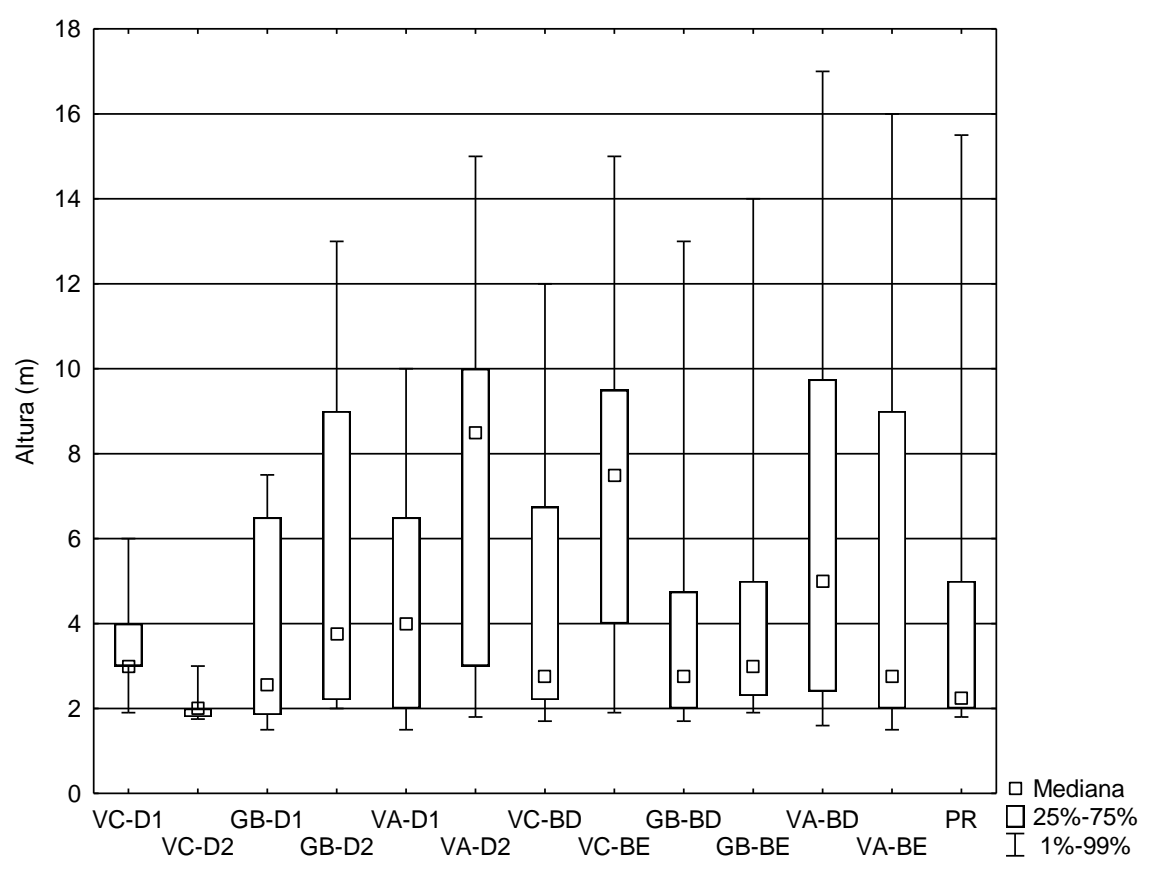

Figura 3: Gráfico boxplot de altura para as áreas de estudo. VA - Vista do Almirante; VC - Vista Chinesa; GB - Gabião; PR - Pai Ricardo; D1 - Domínio 1; D2 - Domínio 2, BD- Borda direita; BE - Borda Esquerda. Fonte: Acervo do Autor.

Em relação a altura (figura 3), o padrão é semelhante ao encontrado para a área basal. Novamente é o Domínio 2 da Vista Chinesa que apresenta o quadro mais degradado, apresentando apenas árvores de baixo porte, e na maior parte com troncos múltiplos. O domínio 1 da vista Chinesa também apresenta baixos valores de altura, o que é esperado pela revegetação induzida por bambu, que não origina indivíduos de grande porte. $\mathrm{O}$ bambu corresponde a $75 \%$ do total de indivíduos encontrados ali, e as outras espécies são pioneiras, como algumas de melastomataceae.

\subsection{Resultados de química de solo}

Tabela 1: Química do solo para os primeiros 5 centímetros de profundidade. Fonte: Acervo do Autor

\begin{tabular}{|c|c|c|c|c|c|c|c|}
\hline Area & $\mathrm{C}(\mathrm{g} / \mathrm{kg})$ & $\mathbf{N}(\mathrm{g} / \mathrm{kg})$ & $P(\mathrm{mg} / \mathrm{kg})$ & $\begin{array}{l}\mathrm{K} \\
\left(\mathrm{cmol}_{\mathrm{c}} / \mathrm{kg}\right)\end{array}$ & pH & $\mathrm{Na}\left(\mathrm{cmol}_{\mathrm{c}} / \mathrm{kg}\right)$ & $\mathrm{Al}\left(\mathrm{cmol}_{\mathrm{c}} / \mathrm{kg}\right)$ \\
\hline VA-D1 & $\begin{array}{l}21,7 \\
( \pm 10,9) \mathrm{ab}\end{array}$ & $\begin{array}{l}1,7( \pm 0,9) \\
\mathrm{ab}\end{array}$ & $\begin{array}{ll}2,7 & ( \pm 1,9) \\
\mathrm{ab} & \end{array}$ & $\begin{array}{ll}0,29 & ( \pm 0,15) \\
\mathrm{a} & \end{array}$ & $\begin{array}{l}5,6( \pm 2,9) \\
\mathrm{a}\end{array}$ & $\begin{array}{ll}0,14 \quad( \pm 0,07) \\
\mathrm{a}\end{array}$ & $0,2( \pm 0,3)$ a \\
\hline VA-D2 & $\begin{array}{l}12,3 \\
( \pm 6,4) \mathrm{a}\end{array}$ & $\begin{array}{l}1,1( \pm 0,6) \\
\mathrm{a}\end{array}$ & $\begin{array}{l}3,3 \quad( \pm 1,4) \\
a b\end{array}$ & $\begin{array}{l}0,53 \quad( \pm 0,37) \\
a\end{array}$ & $\begin{array}{l}5,1( \pm 2,1) \\
\mathrm{ab}\end{array}$ & $\begin{array}{ll}0,10 & ( \pm 0,05) \\
\mathrm{ab} & \end{array}$ & $0,9( \pm 0,7) \mathrm{ab}$ \\
\hline VA-RE & $\begin{array}{l}29,0 \\
( \pm 14,7) \mathrm{ab}\end{array}$ & $\begin{array}{l}2,2( \pm 1,1) \\
a b\end{array}$ & $\begin{array}{ll}2,7 & ( \pm 1,4) \\
\mathrm{ab} & \end{array}$ & $\begin{array}{l}0,53( \pm 0,37) \\
\text { a }\end{array}$ & $\begin{array}{l}4,2( \pm 2,3) \\
b\end{array}$ & $\begin{array}{ll}0,08 & ( \pm 0,04) \\
a b\end{array}$ & $1,4( \pm 0,8) a b$ \\
\hline
\end{tabular}




\begin{tabular}{|c|c|c|c|c|c|c|c|}
\hline VA-LE & $\begin{array}{l}22,1 \\
( \pm 11,9) a b\end{array}$ & $\begin{array}{l}1,6( \pm 0,9) \\
\mathrm{ab}\end{array}$ & $\begin{array}{ll}3,3 & ( \pm 2,5) \\
\mathrm{ab} & \end{array}$ & $\begin{array}{ll}0,23( \pm 0,12) \\
\mathrm{a}\end{array}$ & $\begin{array}{l}4,6( \pm 2,3) \\
\mathrm{ab}\end{array}$ & $\begin{array}{ll}0,09 & ( \pm 0,05) \\
\mathrm{ab} & \end{array}$ & $1,3( \pm 1,0) a b$ \\
\hline GB-D1 & $\begin{array}{l}19,7 \\
( \pm 11,3) a b\end{array}$ & $\begin{array}{l}1,5( \pm 0,8) \\
\mathrm{a}\end{array}$ & $\begin{array}{ll}2,3 & ( \pm 1,2) \\
\mathrm{ab} & \end{array}$ & $\begin{array}{ll}0,17 & ( \pm 0,09) \\
\mathrm{a} & \end{array}$ & $\begin{array}{l}5,5( \pm 2,7) \\
a\end{array}$ & $\begin{array}{ll}0,05 & ( \pm 0,03) \\
b & \end{array}$ & $0,1( \pm 0,1) \mathrm{a}$ \\
\hline GB-D2 & $\begin{array}{l}19,5 \\
( \pm 14,1) \text { ab }\end{array}$ & $\begin{array}{l}1,5( \pm 1,0) \\
\mathrm{a}\end{array}$ & $\begin{array}{l}2,0 \quad( \pm 1,7) \\
a b\end{array}$ & $\begin{array}{l}0,28( \pm 0,19) \\
\text { a }\end{array}$ & $\begin{array}{l}5,2( \pm 2,6) \\
a\end{array}$ & $\begin{array}{ll}0,07 & ( \pm 0,03) \\
\text { b } & \end{array}$ & $0,5( \pm 0$ \\
\hline GB-RE & $\begin{array}{l}23,7 \\
( \pm 12,8) a b\end{array}$ & $\begin{array}{l}2,3( \pm 1,1) \\
\mathrm{ab}\end{array}$ & $\begin{array}{ll}3,0 & ( \pm 1,5) \\
\mathrm{ab} & \end{array}$ & $\begin{array}{l}0,12( \pm 0,06) \\
\mathrm{a}\end{array}$ & $\begin{array}{l}4,0( \pm 2,1) \\
\mathrm{ab}\end{array}$ & $\begin{array}{ll}0,05 & ( \pm 0,02) \\
b & \end{array}$ & $1,5( \pm 0,8) a b$ \\
\hline GB-LE & $\begin{array}{l}17,4 \\
( \pm 8,7) \mathrm{ab}\end{array}$ & $\begin{array}{l}1,7( \pm 0,9) \\
\mathrm{ab}\end{array}$ & $\begin{array}{ll}2,3 & ( \pm 1,5) \\
a b & \end{array}$ & $\begin{array}{l}0,31( \pm 0,16) \\
\text { a }\end{array}$ & $\begin{array}{l}5,0( \pm 2,5) \\
\mathrm{ab}\end{array}$ & $\begin{array}{ll}0,05 & ( \pm 0,03) \\
\mathrm{b} & \end{array}$ & $0,3( \pm 0$ \\
\hline VC-D1 & $\begin{array}{l}15,1 \\
( \pm 7,8) a b\end{array}$ & $\begin{array}{l}1,3( \pm 0,7) \\
\mathrm{ab}\end{array}$ & $\begin{array}{l}1,0 \quad( \pm 0,5) \\
\mathrm{a}\end{array}$ & $\begin{array}{l}0,31 \quad( \pm 0,14) \\
\text { a }\end{array}$ & $\begin{array}{l}5,5( \pm 2,8) \\
\mathrm{a}\end{array}$ & $\begin{array}{ll}0,09 & ( \pm 0,05) \\
\mathrm{ab} & \end{array}$ & $0,2( \pm 0,1) a$ \\
\hline VC-D2 & $\begin{array}{l}13,6( \pm 7,0) \\
\mathrm{a}\end{array}$ & $\begin{array}{l}1,0( \pm 0,6) \\
\mathrm{a}\end{array}$ & $\begin{array}{l}1,0 \quad( \pm 0,5) \\
a\end{array}$ & $\begin{array}{l}0,23( \pm 0,08) \\
\text { a }\end{array}$ & $\begin{array}{l}4,9( \pm 2,4) \\
\mathrm{ab}\end{array}$ & $\begin{array}{ll}0,06 & ( \pm 0,03) \\
\mathrm{ab} & \end{array}$ & $0,8( \pm 0,5) \mathrm{ab}$ \\
\hline VC-RE & $\begin{array}{l}14,9 \\
( \pm 8,0) \mathrm{ab}\end{array}$ & $\begin{array}{l}1,2( \pm 0,8) \\
\mathrm{ab}\end{array}$ & $\begin{array}{ll}1,0 \quad( \pm 0,5) \\
\mathrm{a}\end{array}$ & $\begin{array}{l}0,32 \quad( \pm 0,17) \\
\mathrm{a}\end{array}$ & $\begin{array}{l}4,8( \pm 2,4) \\
\text { ab }\end{array}$ & $\begin{array}{ll}0,09 & ( \pm 0,05) \\
\mathrm{ab} & \end{array}$ & $0,9( \pm 0,6) a b$ \\
\hline VC-LE & $\begin{array}{l}21,6 \\
( \pm 13,8) a b\end{array}$ & $\begin{array}{l}1,8( \pm 1,0) \\
\mathrm{a}\end{array}$ & $\begin{array}{ll} & 1,7 \quad( \pm 1,3) \\
a & \end{array}$ & $\begin{array}{l}0,21 \quad( \pm 0,12) \\
a\end{array}$ & $\begin{array}{l}4,7( \pm 2,3) \\
\mathrm{ab}\end{array}$ & $\begin{array}{ll}0,11 & ( \pm 0,06) \\
\mathrm{ab} & \end{array}$ & $1,1( \pm 0,8) \mathrm{ab}$ \\
\hline PR & $\begin{array}{ll}37,4 & ( \pm \\
2,7) \mathrm{b} & \end{array}$ & $\begin{array}{l}3,1 \\
0,2) \mathrm{b}\end{array}$ & $\begin{array}{l}7,3 \quad( \pm 3,1) \\
b\end{array}$ & $\begin{array}{l}0,14( \pm 0,01) \\
\mathrm{a}\end{array}$ & $\begin{array}{l}3,8( \pm 0,1) \\
b\end{array}$ & $\begin{array}{l}0,06( \pm 0,01) \\
\mathrm{b}\end{array}$ & $2,5( \pm 0,2) b$ \\
\hline
\end{tabular}

VA - Vista do Almirante; VC - Vista Chinesa; GB - Gabião; PR - Pai Ricardo; D1 - Domínio 1; D2 Domínio 2, BD- Borda direita; BE - Borda Esquerda.

Tabela 2: Química do solo para a profundidade de 5-10 cm. Fonte: Acervo do Autor

\begin{tabular}{l|l|l|l|l|l|l|l}
\hline Área & $\mathbf{C}(\mathbf{g} / \mathbf{k g})$ & $\mathbf{N}(\mathbf{g} / \mathbf{k g})$ & $\mathbf{P}(\mathbf{m g} / \mathbf{k g})$ & $\begin{array}{l}\mathbf{K} \\
(\mathbf{c m o l} / \mathbf{k g})\end{array}$ & $\mathbf{p H}$ & $\mathbf{N a}(\mathbf{c m o l} \mathbf{c} / \mathbf{k g})$ & $\mathbf{A l}(\mathbf{c m o l} / \mathbf{k g})$ \\
\hline VA-D1 & $\begin{array}{l}15,2 \\
( \pm 7,8) \mathrm{a}\end{array}$ & $\begin{array}{l}1,3( \pm 0,7) \\
\mathrm{a}\end{array}$ & $\begin{array}{l}2,0( \pm 1,0) \\
\mathrm{ab}\end{array}$ & $\begin{array}{l}0,16( \pm 0,09) \\
\mathrm{a}\end{array}$ & $\begin{array}{l}5,2( \pm 2,6) \\
\mathrm{a}\end{array}$ & $0,11( \pm 0,06) \mathrm{a}$ & $0,5( \pm 0,5) \mathrm{a}$ \\
\hline VA-D2 & $\begin{array}{l}7,8( \pm 4,1) \\
\mathrm{a}\end{array}$ & $\begin{array}{l}0,8( \pm 0,4) \\
\mathrm{a}\end{array}$ & $\begin{array}{l}3,3( \pm 1,7) \\
\mathrm{a}\end{array}$ & $\begin{array}{l}0,23( \pm 0,14) \\
\mathrm{a}\end{array}$ & $\begin{array}{l}4,9( \pm 2,5) \\
\mathrm{ab}\end{array}$ & $\begin{array}{l}0,07( \pm 0,04) \\
\mathrm{ab}\end{array}$ & $1,3( \pm 0,7) \mathrm{ab}$ \\
\hline VA-RE & $\begin{array}{l}18,2 \\
( \pm 9,7) \mathrm{b}\end{array}$ & $\begin{array}{l}1,7( \pm 0,9) \\
\mathrm{b}\end{array}$ & $\begin{array}{l}2,0( \pm 1,9) \\
\mathrm{ab}\end{array}$ & $\begin{array}{l}0,23( \pm 0,14) \\
\mathrm{a}\end{array}$ & $\begin{array}{l}4,1( \pm 2,1) \\
\mathrm{ab}\end{array}$ & $\begin{array}{l}0,07( \pm 0,03) \\
\mathrm{ab}\end{array}$ & $1,3( \pm 0,8) \mathrm{ab}$ \\
\hline VA-LE & $\begin{array}{l}17,2 \\
( \pm 8,8) \mathrm{b}\end{array}$ & $\begin{array}{l}1,4( \pm 0,7) \\
\mathrm{a}\end{array}$ & $\begin{array}{l}3,0( \pm 1,7) \\
\mathrm{a}\end{array}$ & $\begin{array}{l}0,13( \pm 0,07) \\
\mathrm{a}\end{array}$ & $\begin{array}{l}4,3( \pm 2,2) \\
\mathrm{ab}\end{array}$ & $\begin{array}{l}0,06( \pm 0,04) \\
\mathrm{ab}\end{array}$ & $1,6( \pm 1,0) \mathrm{ab}$ \\
\hline GB-D1 & $\begin{array}{l}13,8 \\
( \pm 7,4) \mathrm{a}\end{array}$ & $\begin{array}{l}1,3( \pm 0,7) \\
\mathrm{a}\end{array}$ & $\begin{array}{l}1,0( \pm 0,5) \\
\mathrm{b}\end{array}$ & $\begin{array}{l}0,12( \pm 0,06) \\
\mathrm{a}\end{array}$ & $\begin{array}{l}5,2( \pm 2,6) \\
\mathrm{a}\end{array}$ & $0,04( \pm 0,02) \mathrm{b}$ & $0,3( \pm 0,4) \mathrm{a}$ \\
\hline GB-D2 & $\begin{array}{l}9,4( \pm 5,7) \\
\mathrm{a}\end{array}$ & $\begin{array}{l}1,0( \pm 0,6) \\
\mathrm{a}\end{array}$ & $\begin{array}{l}1,0( \pm 0,5) \\
\mathrm{b}\end{array}$ & $\begin{array}{l}0,25( \pm 0,15) \\
\mathrm{a}\end{array}$ & $\begin{array}{l}4,8( \pm 2,5) \\
\mathrm{ab}\end{array}$ & $\begin{array}{l}0,06( \pm 0,03) \\
\mathrm{ab}\end{array}$ & $0,7( \pm 0,4) \mathrm{ab}$ \\
\hline
\end{tabular}




\begin{tabular}{l|l|l|l|l|l|l|l}
\hline GB-RE & $\begin{array}{l}22,1 \\
\pm 11,2) \mathrm{ab}\end{array}$ & $\begin{array}{l}2,2( \pm 1,1) \\
\mathrm{ab}\end{array}$ & $\begin{array}{l}2,0( \pm 1,0) \\
\mathrm{ab}\end{array}$ & $\begin{array}{l}0,10( \pm 0,05) \\
\mathrm{a}\end{array}$ & $\begin{array}{l}4,2( \pm 2,1) \\
\mathrm{ab}\end{array}$ & $\begin{array}{l}0,04( \pm 0,02) \\
\mathrm{ab}\end{array}$ & $2,1( \pm 1,2) \mathrm{ab}$ \\
\hline GB-LE & $\begin{array}{l}13,6 \\
\pm 6,8) \mathrm{ab}\end{array}$ & $\begin{array}{l}1,5( \pm 0,7) \\
\mathrm{a}\end{array}$ & $\begin{array}{l}1,7( \pm 1,0) \\
\mathrm{ab}\end{array}$ & $\begin{array}{l}0,19( \pm 0,15) \\
\mathrm{a}\end{array}$ & $\begin{array}{l}4,8( \pm 2,4) \\
\mathrm{ab}\end{array}$ & $0,05( \pm 0,02) \mathrm{b}$ & $0,6( \pm 0,3) \mathrm{a}$ \\
\hline VC-D1 & $\begin{array}{l}11,7 \\
( \pm 5,2) \mathrm{a}\end{array}$ & $\begin{array}{l}0,9( \pm 0,5) \\
\mathrm{a}\end{array}$ & $\begin{array}{l}1,0( \pm 0,5) \\
\mathrm{b}\end{array}$ & $\begin{array}{l}0,14( \pm 0,07) \\
\mathrm{a}\end{array}$ & $\begin{array}{l}5,2( \pm 2,6) \\
\mathrm{a}\end{array}$ & $\begin{array}{l}0,06( \pm 0,03) \\
\mathrm{ab}\end{array}$ & $0,3( \pm 0,2) \mathrm{ab}$ \\
\hline VC-D2 & $\begin{array}{l}9,7( \pm 6,0) \\
\mathrm{a}\end{array}$ & $\begin{array}{l}1,0( \pm 0,5) \\
\mathrm{a}\end{array}$ & $\begin{array}{l}1,0( \pm 0,5) \\
\mathrm{b}\end{array}$ & $\begin{array}{l}0,11( \pm 0,05) \\
\mathrm{a}\end{array}$ & $\begin{array}{l}4,7( \pm 2,3) \\
\mathrm{ab}\end{array}$ & $\begin{array}{l}0,06( \pm 0,03) \\
\mathrm{ab}\end{array}$ & $\begin{array}{l}1,2( \pm 0,7) \\
\mathrm{ab}\end{array}$ \\
\hline VC-RE & $\begin{array}{l}10,2 \\
\pm 5,2) \mathrm{a}\end{array}$ & $\begin{array}{l}1,1( \pm 0,6) \\
\mathrm{a}\end{array}$ & $\begin{array}{l}1,0( \pm 0,5) \\
\mathrm{b}\end{array}$ & $\begin{array}{l}0,15( \pm 0,12) \\
\mathrm{a}\end{array}$ & $\begin{array}{l}4,6( \pm 2,3) \\
\mathrm{ab}\end{array}$ & $\begin{array}{l}0,06( \pm 0,03) \\
\mathrm{ab}\end{array}$ & $1,4( \pm 0,8) \mathrm{ab}$ \\
\hline VC-LE & $\begin{array}{l}13,2 \\
( \pm 7,5) \mathrm{a}\end{array}$ & $\begin{array}{l}1,3( \pm 0,7) \\
\mathrm{a}\end{array}$ & $\begin{array}{l}1,0( \pm 0,5) \\
\mathrm{b}\end{array}$ & $\begin{array}{l}0,13( \pm 0,07) \\
\mathrm{a}\end{array}$ & $\begin{array}{l}4,2( \pm 2,2) \\
\mathrm{ab}\end{array}$ & $\begin{array}{l}0,06( \pm 0,03) \\
\mathrm{ab}\end{array}$ & $1,5( \pm 0,8) \mathrm{ab}$ \\
\hline PR & $\begin{array}{l}27,7 \\
( \pm 0,6) \mathrm{b}\end{array}$ & $\begin{array}{l}2,6( \pm \\
0,1) \mathrm{b}\end{array}$ & $\begin{array}{l}2,7( \pm 0.6) \\
\mathrm{ab}\end{array}$ & $\begin{array}{l}0,10( \pm 0,01) \\
\mathrm{a}\end{array}$ & $\begin{array}{l}3,7( \pm 0,1) \\
\mathrm{b}\end{array}$ & $\begin{array}{l}0,04( \pm 0,01) \\
\mathrm{b}\end{array}$ & $2,7( \pm 0,2) \mathrm{b}$ \\
\hline VA $-\mathrm{Vin}$
\end{tabular}

VA - Vista do Almirante; VC - Vista Chinesa; GB - Gabião; PR - Pai Ricardo; D1 - Domínio 1; D2 Domínio 2, BD- Borda direita; BE - Borda Esquerda.

O Pai Ricardo apresenta os maiores valores médios para carbono, nitrogênio e fósforo (tabela 1). O padrão do fósforo é muito interessante, já que a área controle difere significativamente de todos os domínios da Vista Chinesa, o que é um indicador da degeneração desta área. Para o carbono o pai Ricardo apresentou valor significativamente maior que os domínios 2 do Almirante e do gabião, e para o nitrogênio foi significativamente diferente de todos os domínios 2, do domínio 1 do gabião e da borda esquerda da Vista Chinesa.

$\mathrm{O}$ pH do pai Ricardo foi o mais ácido de todas as áreas, sendo significativamente diferente da maior parte das áreas de clareira, que apresentaram pH mais básico. Para o potássio não houve diferenças, padrão que ocorrerá na maior parte das profundidades, e para o sódio houve diferenças significativas apenas entre a área controle e a clareira do gabião em comparação ao Domínio 1 da Vista do Almirante.

Tabela 3: Química do solo para a profundidade de $10-20 \mathrm{~cm} \quad$. Fonte: Acervo do Autor

\begin{tabular}{l|l|l|l|l|l|l|l}
\hline área & $\mathbf{C}(\mathbf{g} / \mathbf{k g})$ & $\mathbf{N}(\mathbf{g} / \mathbf{k g})$ & $\mathbf{P}(\mathbf{m g} / \mathbf{k g})$ & $\mathbf{K}(\mathbf{c m o l} / \mathbf{k g})$ & $\mathbf{p H}$ & $\mathbf{N a}(\mathbf{c m o l} / \mathbf{k g})$ & $\mathbf{A l}(\mathbf{c m o l} / \mathbf{k g})$ \\
\hline VA-D1 & $\begin{array}{l}13,3 \\
( \pm 7,0) \text { a }\end{array}$ & $\begin{array}{l}1,1( \pm 0,6) \\
\mathrm{a}\end{array}$ & $\begin{array}{l}2,0( \pm 1,0) \\
\mathrm{ab}\end{array}$ & $\begin{array}{l}0,16( \pm 0,09) \\
\mathrm{a}\end{array}$ & $\begin{array}{l}5,2( \pm 2,6) \\
\mathrm{a}\end{array}$ & $\begin{array}{l}0,09( \pm 0,05) \\
\mathrm{a}\end{array}$ & $0,6( \pm 0,5) \mathrm{a}$ \\
\hline VA-D2 & $\begin{array}{l}5,9 \\
( \pm 3,4) \mathrm{a}\end{array}$ & $\begin{array}{l}0,6( \pm 0,3) \\
\mathrm{a}\end{array}$ & $\begin{array}{l}4,0( \pm 1,0) \\
\mathrm{b}\end{array}$ & $\begin{array}{l}0,20( \pm 0,11) \\
\mathrm{a}\end{array}$ & $\begin{array}{l}4,8( \pm 2,4) \\
\mathrm{ab}\end{array}$ & $0,04( \pm 0,04) \mathrm{a}$ & $1,5( \pm 0,7) \mathrm{ab}$ \\
\hline
\end{tabular}




\begin{tabular}{|c|c|c|c|c|c|c|c|}
\hline VA-RE & $\begin{array}{l}16,2 \\
( \pm 8,0) a b\end{array}$ & $\begin{array}{l}1,5(\underline{+0,7)} \\
\mathrm{ab}\end{array}$ & $\begin{array}{l}1,7( \pm 2,2) \\
a\end{array}$ & $\begin{array}{l}0,20( \pm 0,11) \\
\mathrm{a}\end{array}$ & $\begin{array}{l}4,2( \pm 2,1) \\
\mathrm{ab}\end{array}$ & $0,05( \pm 0,03)$ a & $1,5( \pm 0,8) \mathrm{ab}$ \\
\hline VA-LE & $\begin{array}{l}14,7 \\
( \pm 7,3) \mathrm{ab}\end{array}$ & $\begin{array}{l}1,3( \pm 0,8) \\
\mathrm{ab}\end{array}$ & $\begin{array}{l}1,7( \pm 1,3) \\
\mathrm{a}\end{array}$ & $\begin{array}{l}0,12( \pm 0,06) \\
\mathrm{a}\end{array}$ & $\begin{array}{l}4,3( \pm 2,2) \\
\mathrm{ab}\end{array}$ & $0,06( \pm 0,03) \mathrm{a}$ & $1,5( \pm 1,0) \mathrm{ab}$ \\
\hline GB-D1 & $\begin{array}{l}9,6 \\
( \pm 4,8) \text { a }\end{array}$ & $\begin{array}{l}1,0( \pm 0,5) \\
\mathrm{a}\end{array}$ & $\begin{array}{l}1,0( \pm 0,5) \\
\mathrm{a}\end{array}$ & $\begin{array}{l}0,09( \pm 0,05) \\
\mathrm{a}\end{array}$ & $\begin{array}{l}5,1( \pm 2,5) \\
a\end{array}$ & $\begin{array}{l}0,03( \pm 0,02) \\
\mathrm{a}\end{array}$ & $0,5( \pm 0,4) \mathrm{a}$ \\
\hline GB-D2 & $\begin{array}{l}6,8 \\
( \pm 3,9) \mathrm{a}\end{array}$ & $\begin{array}{l}0,7( \pm 0,4) \\
\mathrm{a}\end{array}$ & $\begin{array}{l}1,0( \pm 0,5) \\
\mathrm{a}\end{array}$ & $\begin{array}{l}0,26( \pm 0,13) \\
\mathrm{a}\end{array}$ & $\begin{array}{l}5,1( \pm 2,5) \\
a\end{array}$ & $0,04( \pm 0,02) \mathrm{a}$ & $\begin{array}{l}0,9( \pm 0,5) \\
a b\end{array}$ \\
\hline GB-RE & $\begin{array}{l}19,0 \\
( \pm 9,6) \mathrm{ab}\end{array}$ & $\begin{array}{l}1,9( \pm 1,0) \\
a b\end{array}$ & $\begin{array}{l}1,7( \pm 1,0) \\
\mathrm{a}\end{array}$ & $\begin{array}{l}0,08( \pm 0,04) \\
\mathrm{a}\end{array}$ & $\begin{array}{l}4,1( \pm 2,1) \\
\mathrm{ab}\end{array}$ & $0,04( \pm 0,02) \mathrm{a}$ & $\begin{array}{l}2,2( \pm 1,2) \\
a b\end{array}$ \\
\hline GB-LE & $\begin{array}{l}11,5 \\
( \pm 5,9) \mathrm{ab}\end{array}$ & $\begin{array}{l}1,3( \pm 0,7) \\
\mathrm{ab}\end{array}$ & $\begin{array}{l}1,0( \pm 0,5) \\
\mathrm{a}\end{array}$ & $\begin{array}{l}0,27( \pm 0,15) \\
\mathrm{a}\end{array}$ & $\begin{array}{l}4,9( \pm 2,5) \\
a\end{array}$ & $0,04( \pm 0,02) \mathrm{a}$ & $0,6( \pm 0,3) a$ \\
\hline VC-D1 & $\begin{array}{l}9,7 \\
( \pm 4,6) \mathrm{a}\end{array}$ & $\begin{array}{l}0,6( \pm 0,3) \\
\mathrm{a}\end{array}$ & $\begin{array}{l}0,8( \pm 0,5) \\
\mathrm{a}\end{array}$ & $\begin{array}{l}0,10( \pm 0,05) \\
\mathrm{a}\end{array}$ & $\begin{array}{l}4,9( \pm 2,5) \\
a\end{array}$ & $0,05( \pm 0,03) \mathrm{a}$ & $0,7( \pm 0,3) \mathrm{a}$ \\
\hline VC-D2 & $\begin{array}{l}11,7 \\
( \pm 5,2) \mathrm{a}\end{array}$ & $\begin{array}{l}0,9( \pm 0,5) \\
\mathrm{a}\end{array}$ & $\begin{array}{l}0,8( \pm 0,5) \\
\mathrm{a}\end{array}$ & $\begin{array}{l}0,09( \pm 0,05) \\
\mathrm{a}\end{array}$ & $\begin{array}{l}4,5( \pm 2,3) \\
\mathrm{a}\end{array}$ & $0,05( \pm 0,03) \mathrm{a}$ & $\begin{array}{l}1,4( \pm 0,7) \\
a b\end{array}$ \\
\hline VC-RE & $\begin{array}{l}10,2 \\
( \pm 3,9) \mathrm{a}\end{array}$ & $\begin{array}{l}0,8( \pm 0,4) \\
\mathrm{a}\end{array}$ & $\begin{array}{l}0,8( \pm 0,5) \\
\mathrm{a}\end{array}$ & $\begin{array}{l}0,16( \pm 0,09) \\
\mathrm{a}\end{array}$ & $\begin{array}{l}4,4( \pm 2,2) \\
a\end{array}$ & $0,05( \pm 0,03) \mathrm{a}$ & $\begin{array}{l}1,6( \pm 0,8) \\
a b\end{array}$ \\
\hline VC-LE & $\begin{array}{l}13,4 \\
( \pm 5,5) \mathrm{a}\end{array}$ & $\begin{array}{l}1,0( \pm 0,6) \\
\mathrm{a}\end{array}$ & $\begin{array}{l}0,8( \pm 0,5) \\
\mathrm{a}\end{array}$ & $\begin{array}{l}0,10( \pm 0,06) \\
\mathrm{a}\end{array}$ & $\begin{array}{l}4,4( \pm 2,2) \\
\mathrm{a}\end{array}$ & $0,05( \pm 0,03) \mathrm{a}$ & $\begin{array}{l}1,5( \pm 0,8) \\
a b\end{array}$ \\
\hline PR & $\begin{array}{l}20,2 \\
( \pm 2,5) \mathrm{b}\end{array}$ & $\begin{array}{l}2,1( \pm 0,3) \\
b\end{array}$ & $\begin{array}{l}2,7( \pm 0.6) \\
a b\end{array}$ & $\begin{array}{l}0,10( \pm 0,04) \\
\mathrm{a}\end{array}$ & $\begin{array}{l}3,8( \pm 0,1) \\
\mathrm{b}\end{array}$ & $\begin{array}{l}0,03( \pm 0,01) \\
\mathrm{a}\end{array}$ & $2,4( \pm 0,1) b$ \\
\hline
\end{tabular}

VA - Vista do Almirante; VC - Vista Chinesa; GB - Gabião; PR - Pai Ricardo; D1 - Domínio 1; D2 -

Domínio 2, BD- Borda direita; BE - Borda Esquerda.

Tabela 4: Química do solo para a profundidade de $20-40 \mathrm{~cm}$. Fonte: Acervo do Autor

\begin{tabular}{l|l|l|l|l|l|l|l}
\hline Área & $\mathbf{C}(\mathbf{g} / \mathbf{k g})$ & $\mathbf{N}(\mathbf{g} / \mathbf{k g})$ & $\begin{array}{l}\mathbf{P} \\
(\mathbf{m g} / \mathbf{k g})\end{array}$ & $\begin{array}{l}\mathbf{K} \\
\left(\mathbf{c m o l}_{\mathbf{c}} / \mathbf{k g}\right)\end{array}$ & $\mathbf{p H}$ & $\mathbf{N a}(\mathbf{c m o l} / \mathbf{k g})$ & $\begin{array}{l}\mathbf{A} \mathbf{l} \\
(\mathbf{c m o l} / \mathbf{k g})\end{array}$ \\
\hline VA-D1 & $\begin{array}{l}12,4( \pm 6,4) \\
\mathrm{ab}\end{array}$ & $1,1( \pm 0,6) \mathrm{a}$ & $\begin{array}{l}2,0 \\
( \pm 1,0) \mathrm{a}\end{array}$ & $\begin{array}{l}0,17 \\
( \pm 0,10) \mathrm{a}\end{array}$ & $5,0( \pm 2,6) \mathrm{a}$ & $0,09( \pm 0,05) \mathrm{a}$ & $0,9( \pm 0,8) \mathrm{a}$ \\
\hline VA-D2 & $3,6( \pm 2,1) \mathrm{a}$ & $\begin{array}{l}0,4( \pm 0,2) \\
\mathrm{ab}\end{array}$ & $\begin{array}{l}2,9 \\
( \pm 1,0) \mathrm{b}\end{array}$ & $\begin{array}{l}0,17 \\
( \pm 0,09) \mathrm{a}\end{array}$ & $\begin{array}{l}4,0( \pm 2,5) \\
\mathrm{ab}\end{array}$ & $0,04( \pm 0,02) \mathrm{a}$ & $1,5( \pm 0,8) \mathrm{a}$ \\
\hline VA-RE & $\begin{array}{l}12,6( \pm 6,3) \\
\mathrm{ab}\end{array}$ & $\begin{array}{l}1,3( \pm 0,7) \\
\mathrm{ab}\end{array}$ & $\begin{array}{l}1,0 \\
( \pm 3,7) \mathrm{a}\end{array}$ & $\begin{array}{l}0,13 \\
( \pm 0,09) \mathrm{a}\end{array}$ & $\begin{array}{l}4,4( \pm 2,2) \\
\mathrm{ab}\end{array}$ & $0,04( \pm 0,02) \mathrm{a}$ & $1,4( \pm 0,7) \mathrm{a}$ \\
\hline VA-LE & $\begin{array}{l}10,7( \pm 5,6) \\
\mathrm{ab}\end{array}$ & $\begin{array}{l}1,1( \pm 0,6) \\
\mathrm{ab}\end{array}$ & $\begin{array}{l}2,0 \\
( \pm 0,5) \mathrm{a}\end{array}$ & $\begin{array}{l}0,10 \\
( \pm 0,06) \mathrm{a}\end{array}$ & $\begin{array}{l}4,4( \pm 2,2) \\
\mathrm{ab}\end{array}$ & $0,05( \pm 0,03) \mathrm{a}$ & $1,5( \pm 0,8) \mathrm{a}$ \\
\hline GB-D1 & $\begin{array}{l}7,4( \pm 3,8) \\
\mathrm{ab}\end{array}$ & $0,8( \pm 0,4) \mathrm{a}$ & $\begin{array}{l}0,5 \\
( \pm 0,3) \mathrm{a}\end{array}$ & $\begin{array}{l}0,06 \\
( \pm 0,04) \mathrm{a}\end{array}$ & $\begin{array}{l}4,8( \pm 2,4) \\
\mathrm{ab}\end{array}$ & $\begin{array}{l}0,02( \pm 0,01) \\
\mathrm{a}\end{array}$ & $0,7( \pm 0,4) \mathrm{a}$ \\
\hline
\end{tabular}




\begin{tabular}{|c|c|c|c|c|c|c|c|}
\hline GB-D2 & $4,7( \pm 2,7)$ a & $0,6( \pm 0,3) \mathrm{a}$ & $\begin{array}{l}1,0 \\
( \pm 0,5) \mathrm{a}\end{array}$ & $\begin{array}{l}0,22 \\
( \pm 0,13) \text { a }\end{array}$ & $5,0( \pm 2,5)$ a & $0,04( \pm 0,02) a$ & $0,9( \pm 0,5) \mathrm{a}$ \\
\hline GB-RE & $\begin{array}{l}15,7( \pm 8,1) \\
a b\end{array}$ & $\begin{array}{l}1,6( \pm 0,8) \\
\mathrm{ab}\end{array}$ & $\begin{array}{l}1,7 \\
( \pm 1,0) \mathrm{a}\end{array}$ & $\begin{array}{l}0,07 \\
( \pm 0,04) \mathrm{a}\end{array}$ & $\begin{array}{l}4,0( \pm 2,1) \\
a b\end{array}$ & $0,04( \pm 0,02) a$ & $2,3( \pm 1,2) \mathrm{a}$ \\
\hline GB-LE & $\begin{array}{l}10,7( \pm 5,6) \\
a b\end{array}$ & $\begin{array}{l}1,1( \pm 0,6) \\
a b\end{array}$ & $\begin{array}{l}1,0 \\
( \pm 0,5) \mathrm{a}\end{array}$ & $\begin{array}{l}0,25 \\
( \pm 0,13) \mathrm{a}\end{array}$ & $4,9( \pm 2,5) \mathrm{a}$ & $0,03( \pm 0,02) \mathrm{a}$ & $0,7( \pm 0,3) \mathrm{a}$ \\
\hline VC-D1 & $7,7( \pm 3,4)$ a & $0,6( \pm 0,3) \mathrm{a}$ & $\begin{array}{l}0,8 \\
( \pm 0,5) \mathrm{a}\end{array}$ & $\begin{array}{l}0,07 \\
( \pm 0,03) \mathrm{a}\end{array}$ & $\begin{array}{l}4,8( \pm 2,4) \\
a b\end{array}$ & $0,04( \pm 0,02) a$ & $0,7( \pm 0,4) \mathrm{a}$ \\
\hline VC-D2 & $\begin{array}{l}9,9( \pm 4,4) \\
\mathrm{ab}\end{array}$ & $0,8( \pm 0,4) \mathrm{a}$ & $\begin{array}{l}1,0 \\
( \pm 0,5) \mathrm{a}\end{array}$ & $\begin{array}{l}0,07 \\
( \pm 0,04) \mathrm{a}\end{array}$ & $\begin{array}{l}4,4( \pm 2,3) \\
a b\end{array}$ & $0,04( \pm 0,02) \mathrm{a}$ & $1,4( \pm 0,7) \mathrm{a}$ \\
\hline VC-RE & $7,5( \pm 3,0)$ a & $\begin{array}{l}0,7( \pm 0,3) \\
a b\end{array}$ & $\begin{array}{l}0,5 \\
( \pm 0,3) \mathrm{a}\end{array}$ & $\begin{array}{l}0,12 \\
( \pm 0,06) \mathrm{a}\end{array}$ & $\begin{array}{l}4,3( \pm 2,2) \\
a b\end{array}$ & $0,03( \pm 0,02) \mathrm{a}$ & $1,6( \pm 0,8) \mathrm{a}$ \\
\hline VC-LE & $\begin{array}{l}9,9( \pm 3,6) \\
a\end{array}$ & $\begin{array}{l}0,8( \pm 0,4) \\
\mathrm{ab}\end{array}$ & $\begin{array}{l}0,7 \\
( \pm 0,4) \mathrm{a}\end{array}$ & $\begin{array}{l}0,06 \\
( \pm 0,04) \text { a }\end{array}$ & $\begin{array}{l}4,3( \pm 2,2) \\
a b\end{array}$ & $0,04( \pm 0,02) \mathrm{a}$ & $1,5( \pm 0,8) \mathrm{a}$ \\
\hline PR & $\begin{array}{l}14,1( \pm 3,5) \\
b\end{array}$ & $1,5( \pm 0,2) b$ & $\begin{array}{l}1,7 \\
( \pm 0.6) \mathbf{a}\end{array}$ & $\begin{array}{l}0,07( \pm \\
0,03) \mathrm{a}\end{array}$ & $3,9( \pm 0,1) b$ & $\begin{array}{l}0,02( \pm 0,01) \\
\mathrm{a}\end{array}$ & $2,0( \pm 0,2) \mathrm{a}$ \\
\hline
\end{tabular}

VA - Vista do Almirante; VC - Vista Chinesa; GB - Gabião; PR - Pai Ricardo; D1 - Domínio 1; D2 -

Domínio 2, BD- Borda direita; BE - Borda Esquerda.

$\mathrm{Na}$ profundidade de 5-10 centímetros (tabela 2), assim como na de 0-5 cm, a maior concentração de carbono está na área controle, que difere significativamente de todos os domínios 1 e 2 e das bordas da Vista Chinesa. Este é um resultado interessante, já que leva em conta a incorporação de matéria orgânica em profundidades maiores, o que destaca ainda mais a diferença entre as áreas. O padrão é o mesmo para o nitrogênio, e o fósforo apresenta os menores valores na área da clareira da Vista chinesa, que difere significativamente em todos os seus domínios dos domínios do domínio 2 e da borda esquerda da Vista do Almirante. Novamente chama a atenção a elevada concentração de fósforo no Domínio 2 da Vista do Almirante, fato que não havia sido observado em estudos anteriores na área (CHIROL, 2003).

O Pai Ricardo novamente apresentou pH mais ácido, enquanto as áreas de clareira tiveram uma tendência a um pH mais básica (mas ainda assim ácido). Novamente o potássio não apresentou diferenças significativas entre as áreas, e o alumínio apresentou o mesmo padrão encontrado para a profundidade de $0-5 \mathrm{~cm}$.

Para o carbono e nitrogênio houve rigorosamente o mesmo padrão da profundidade anterior (tabela 3), o que destaca ainda mais o papel da incorporação da matéria orgânica no solo na concentração destes nutrientes. Já para o fósforo o maior valor (que destoa dos demais inclusive) é 
o do domínio 2 da Vista do Almirante, como já havia acontecido em menor intensidade na profundidade de $5-10 \mathrm{~cm}$.

Novamente o pH mais ácido é o do pai Ricardo, e não ocorrem diferenças significativas entre as áreas para o potássio e sódio. O Alumínio no Pai Ricardo difere significativamente dos domínios 1 em todas as áreas e da borda esquerda do gabião.

A tabela acima (tabela 4) nos mostra que para o carbono e nitrogênio a área controle apresentou valores significativamente mais altos que a Vista Chinesa e a maior parte das áreas internas das clareiras. Já o fósforo apresentou diferenças significativas apenas para o Domínio 2 da Vista do Almirante.

Como ocorreu em todas as áreas, o pH mais ácido foi encontrado na área controle, mesmo nesta profundidade, mas não foram encontradas diferenças significativas para sódio, alumínio e potássio para nenhuma das áreas nesta profundidade.

Um aspecto interessante é que os nutrientes vão diminuindo em relação a disponibilidade a medida que a profundidade aumenta, destacando o papel do sub-sistema decompositor na preservação deste sistema, como já foi apontado na literatura por diversos outros autores (Brown et al, 1990 a) é interessante notar que as diferenças entre as áreas, principalmente para o carbono, são percebidas também na comparação entre profundidades. Isto só não ocorre com o fósforo, que apresenta concentrações mais elevadas apenas nos primeiros centímetros do solo.

\subsection{Resultados de fauna de microartrópodes}

\subsection{1 Área laboratório 1 - Vista do Almirante}

A figura 3 mostra um padrão que já seria esperado, e que já foi observado na mesma área em Chirol (2003). A Borda direita, em função do maior volume de serrapilheira, que disponibiliza mais recursos e dá origem a um maior número de microhabitats, apresenta uma maior densidade de microartrópodes, enquanto o domínio 2 apresenta a menor densidade. Vale lembrar que o domínio 2 é a área de decomposição mais `rápida, logo existem menos recursos e habitats para a fauna. Em todas as áreas a fauna foi mais numerosa na camada $\mathrm{O}_{2}$, em função das condições mais favoráveis, e menores nas camadas do solo $(0-5 \mathrm{~cm}$ e $5-10 \mathrm{~cm})$. De maneira geral os oribátidos (acari) são o grupo mais numeroso, e a borda direita é a única área que apresenta uma significativa fauna na profundidade de 5-10 cm, já que praticamente não ocorrem animais nesta profundidade nos outros domínios. Chirol (2003) e Castro Jr (1991) já observaram que a fauna pode flutuar em função da precipitação, mas como a precipitação foi bem dentro da média, com um mês mais seco anterior, a 
fauna se encontra dentro do que seria esperado, com maior concentração nas camadas orgânicas do solo e menor nas minerais.

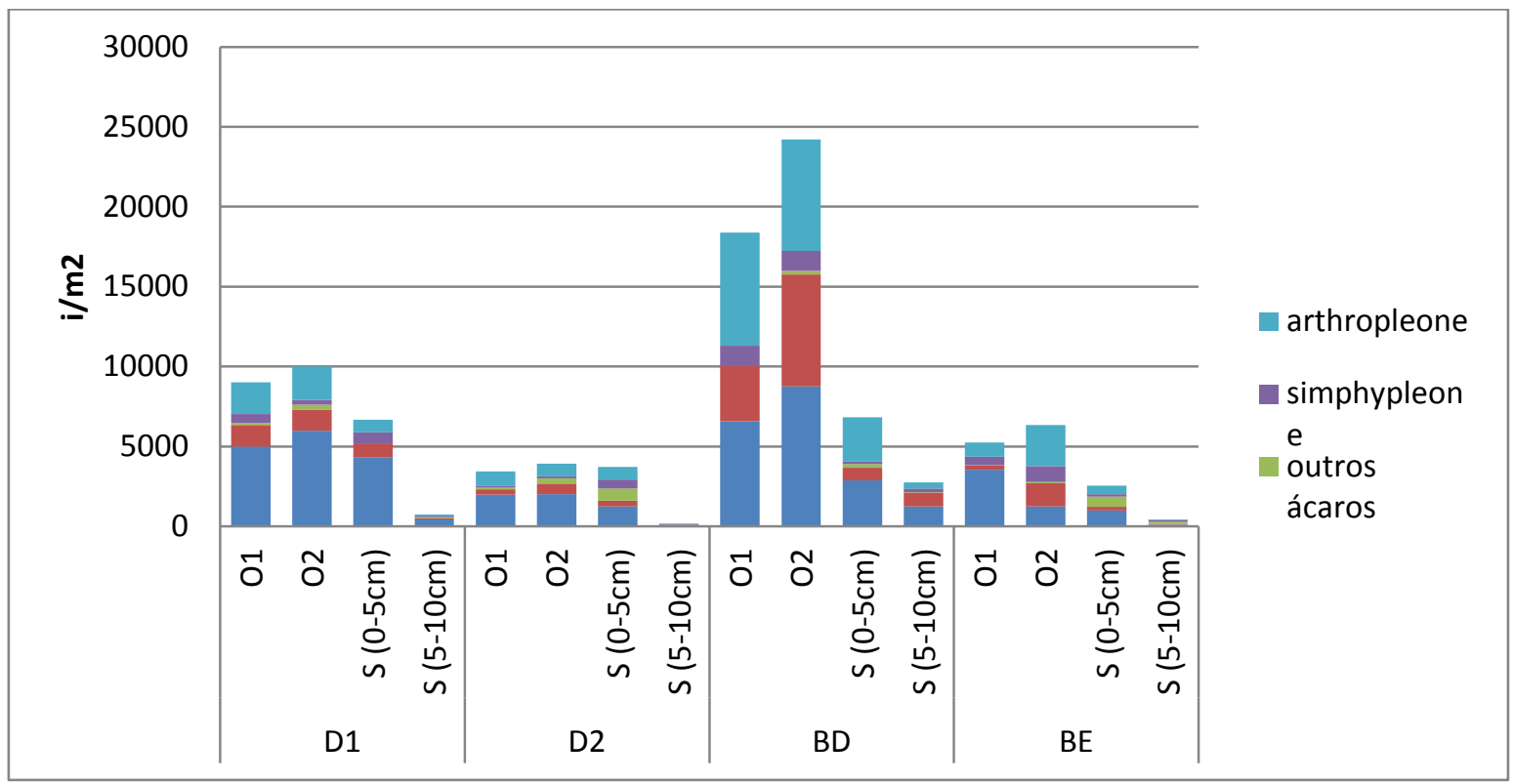

Figura 3: Densidade de microartrópodes na Vista do Almirante. D1 - Domínio 1 D2 - Domínio 2; BD Borda Direita; BE - Borda Esquerda. Fonte: Acervo do Autor.

\subsection{2 Área Laboratório 2 - Vista Chinesa}

Chama a atenção nestas áreas (figura 4) a baixa densidade nos domínios da clareira (D1 e D2). No primeiro, mesmo com as tentativas de revegetação pelo bambu, não houve uma colonização efetiva da área pela fauna, e na segunda as condições são muito inóspitas a estes organismos, com elevada luminosidade e baixa disponibilidade de recursos. Assim a fauna nesta área só é encontrada em maiores densidades nas bordas, e mesmo assim com padrões diferentes das demais áreas, o que pode ser um indicativo da elevada degeneração que esta área está sofrendo. Por exemplo, a densidade de oribátidos na camada $\mathrm{O}_{2}$ na borda esquerda foi muito baixa, o que pode ser um desses indícios de degeneração. Na borda direita a maior parte da fauna está disposta na própria serrapilheira, enquanto na borda esquerda a distribuição é menos concentrada. 


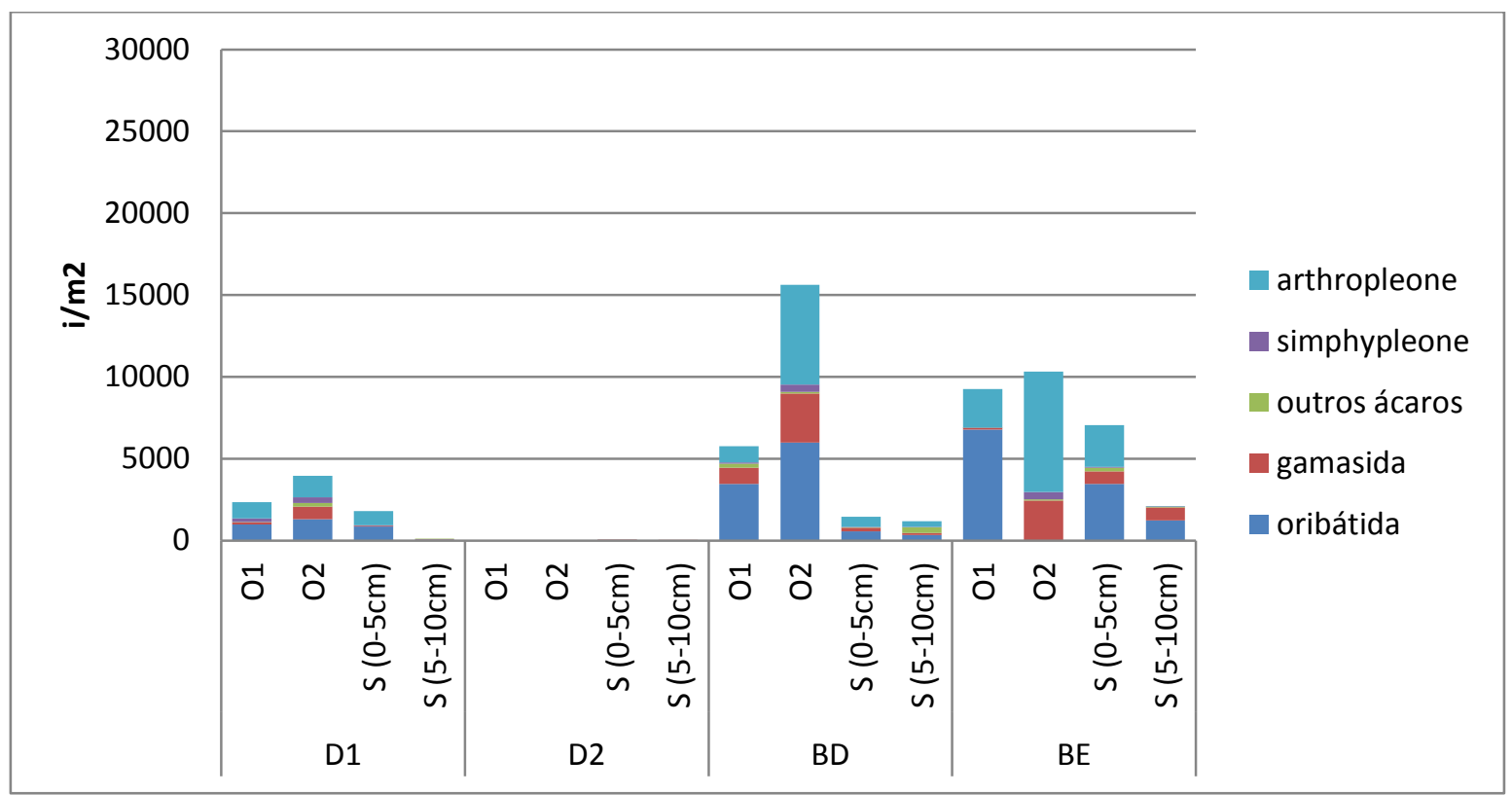

Figura 4: Densidade de microartrópodes na Vista Chinesa. D1 - Domínio 1 D2 - Domínio 2; BD - Borda Direita; BE - Borda Esquerda. Fonte: Acervo do Autor.

\subsection{4 Área Laboratório 3 - Clareira do Gabião}

É interessante notar que nesta área tanto o domínio 1 como as bordas apresentam densidade mais altas (figura 5). Apenas o domínio 2, que tem predomínio de pteridófitas, apresenta baixas densidade de microartrópodes. É interessante notar também que, ao contrário do que ocorre na Vista do Almirante, a segunda camada mais representativa (a primeira é $\mathrm{O}_{2}$ ) são os 5 primeiros centímetros do solo, e não a camada $\mathrm{O}_{1}$. Os oribátidos são o grupo mais representativo, seguido pelo arthropleones (collembola), e este estão principalmente localizados nas bordas, onde as condições de luminosidade são mais favoráveis. Novamente a fauna tem baixíssimas densidades na profundidade de $5-10 \mathrm{~cm}$. 


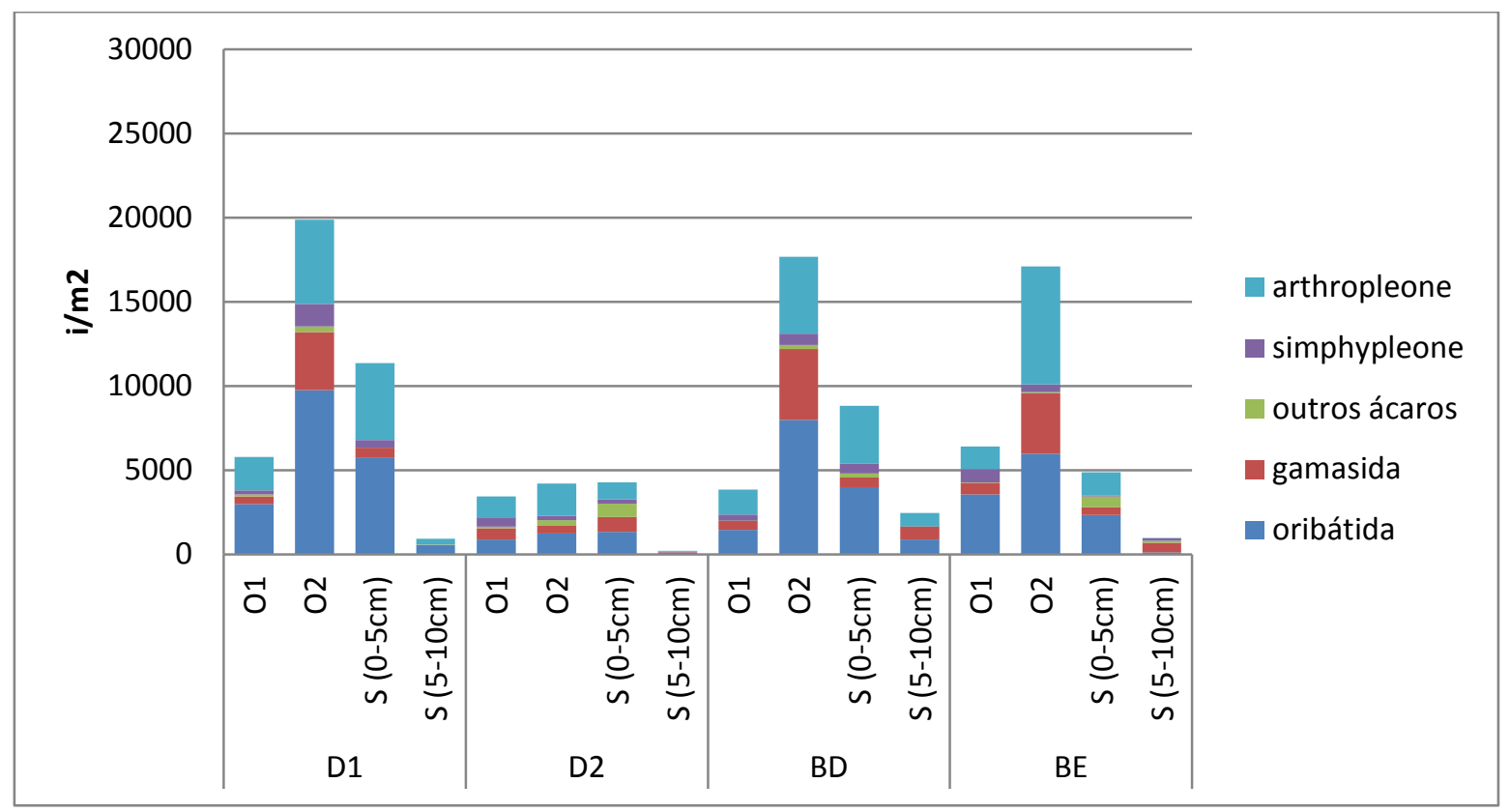

Figura 5: densidade de microartrópodes na clareira do Gabião. D1 - Domínio 1 D2 - Domínio 2; BD Borda Direita; BE - Borda Esquerda. Fonte: Acervo do Autor.

\subsubsection{Mata do Pai Ricardo}

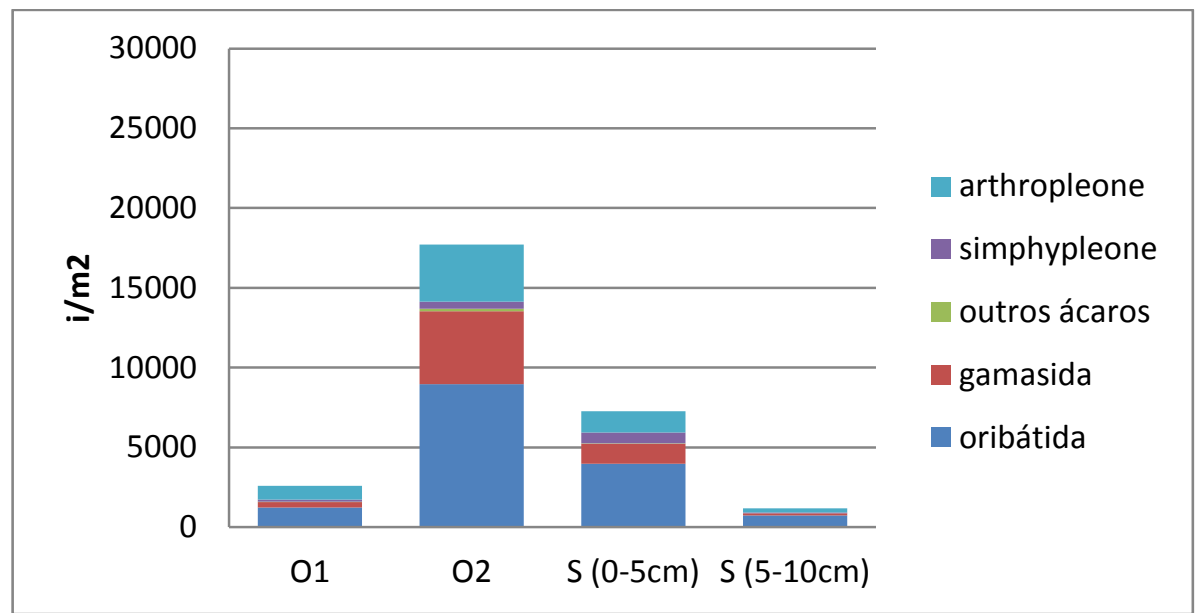

Figura 6: Densidade de microartrópodes na Mata do pai Ricardo. D1 - Domínio 1 D2 - Domínio 2; BD Borda Direita; BE - Borda Esquerda. Fonte: Acervo do Autor.

Em todas as camadas a maior parte da fauna é composta de oribátidos, e a camada $\mathrm{O}_{2}$ é a mais populosa (figura 6), como já seria esperado de acordo com Andersen (1977). A camada $\mathrm{O}_{1}$ tem uma densidade menor que os primeiros $5 \mathrm{~cm}$ do solo, o que pode ser reflexo da rápida e eficiente decomposiçào desta área, que não permite um acúmulo maior da camada $\mathrm{O}_{1}$. A camada com menor 
concentração é a do solo de 5-10 cm, que já era esperado, em função das condições menos favoráveis de recursos.

\subsection{Relação solo fauna}

A figura 7 mostra que, assim como a relação entre decomposição e fauna, a relação não é linear, mas apresenta uma tendência ao aumento do teor de carbono com o aumento da densidade da fauna de microartrópodes do solo. O carbono foi escolhido para a análise pela sua relação direta com o teor de matéria orgânica do solo, que é a principal fonte de nutrientes para áreas tropicias. Mas cabe destacar que o ponto de densidade de fauna mais baixo (domínio 2 da vista chinesa) não é o que apresenta o valor mais baixo de carbono, e sim o domínio 2, que é a área de estudo com decomposição mais rápida. Este rápido turnover pode levar a uma rápida incorporação de matéria orgânica, que é rapidamente mineralizada ou perdida por lavagem, e com isso apresentando o padrão descrito.

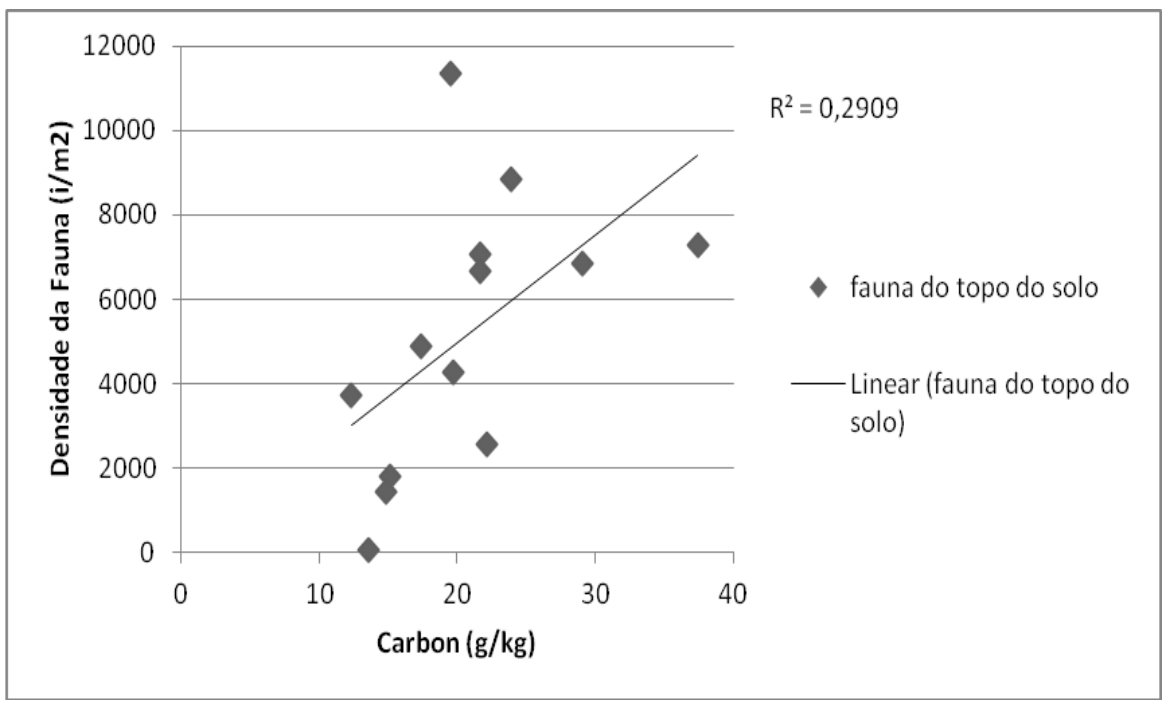

Figura 7: relação fauna dos primeiros $5 \mathrm{~cm}$ do solo com a teor de carbono do solo. Fonte: Acervo do Autor.

Tanto o fósforo como o nitrogênio (figura 8) apresentam relações semelhantes à do carbono, com tendências não lineares ao seu aumento com o aumento da densidade da fauna. É importante firmar que apesar da disponibilidade de nutrientes em florestas tropicais estar fortemente associada a decomposição, a fauna de microartrópodes funciona mais como uma reguladora deste processo do que como agente direto (Swift ET AL, 1979), já que fungos e bactérias são os principais decompositores e a fauna atua como um agente fragmentador, aumentando a superfície específica 
do material foliar e facilitando a decomposição. Mas de qualquer forma, o resultado é um indicativo da importância da fauna para a ciclagem na área.

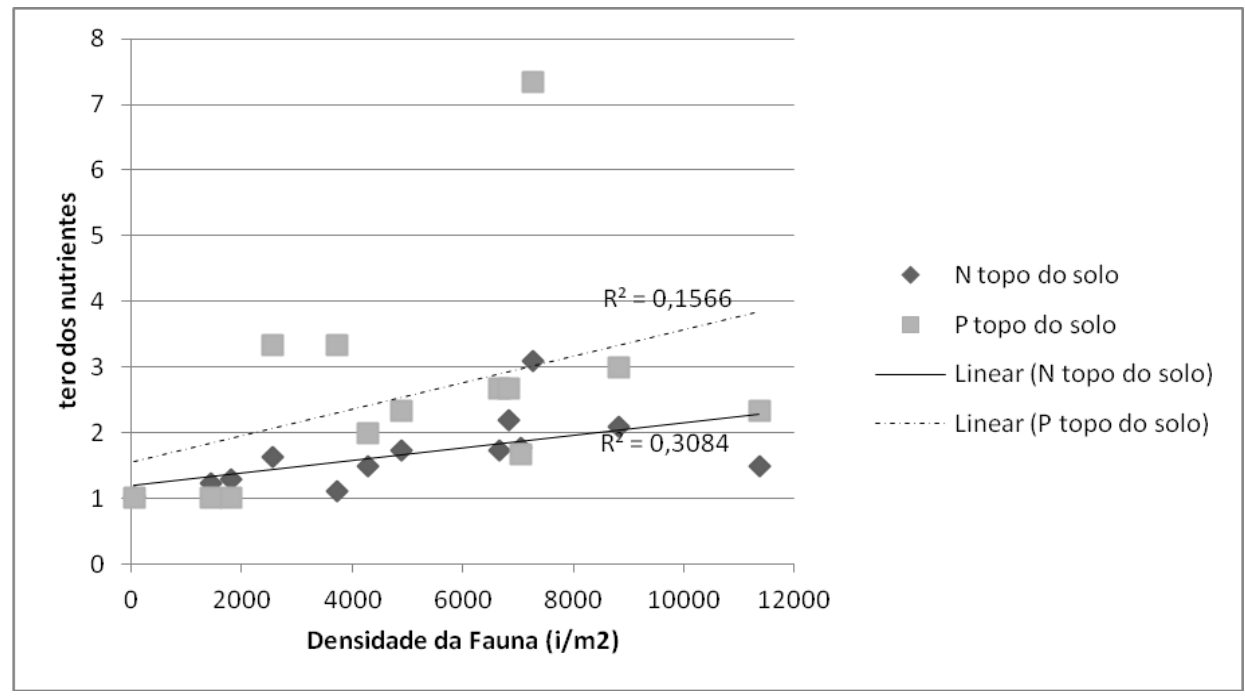

Figura 8: relação fauna dos primeiros $5 \mathrm{~cm}$ do solo com a teor de nitrogênio e fósforo do solo. Fonte: Acervo do Autor.

\section{CONCLUSÃO}

Um dos aspectos que chamam a atenção quando se fala em estrutura da vegetação é que a evolução da sucessão não ocorre de acordo com o modelo proposto por Guariguata ET AL (2001), já que nas clareiras de maior dimensão e forma menos favorável à revegetação não houve o fechamento do dossel, e nem o ganho de biomassa foi intenso, como seria esperado. O padrão pode estar associado ao fato de que no trabalho citado foram utilizadas como referência diversas áreas de pastagem ou queimada, que ao contrário do que ocorrem nas clareiras por deslizamento, apresentam condições pretéritas mais favoráveis de solo. Desta forma, em função deste "tempo zero" das clareiras, onde o solo é praticamente o saprolito exposto, as condições para a sucessão são mais adversas.

As áreas de média encosta (domínio 2) representam a área de sucessão mais complexa, muito em função da própria dinâmica hidro-erosiva, já que os fluxos superficiais, que predominam nas áreas de clareira (Larsen et al, 1999), em substituição aos subsuperficiais, ganham velocidade e dificultam a fixação da vegetação e removem nutrientes. Assim projetos de recuperação e reflorestamento em clareiras devem observar estes padrões, o que provavelmente aumentará a sua taxa de sucesso. 
O topo do solo é o principal compartimento de nutrientes disponíveis para a vegetação, já que a maior parte dos nutrientes se encontra retido na biomassa, como uma estratégia para a conservação de nutrientes típica de áreas tropicais. Brown \& Lugo (1990b) observou que florestas secundárias parecem ter como estratégia uma rápida acumulação de nutrientes na vegetação, que retorna ao solo acompanhado por um rápido "turnover" e absorção pelas raízes. Estes são mecanismos que possibilitam a sobrevivência das comunidades em um ambiente com pouca disponibilidade de nutrientes no solo, através da minimização das perdas. A comparação entre os valores encontrados na área controle e nas áreas laboratório deixa isto bem evidente. Assim como foi visto por Campo et al (2007), o fósforo é o elemento mais crítico para a vegetação, e a sua disponibilidade é muito inferior nas áreas de borda e perturbadas em relação a área controle. Galicia et al (2008) destacam que a composição da vegetação é importantíssima para a disponibilidade de nutrientes, padrão que foi observado neste estudo, principalmente se compararmos a área laboratório 1 (Vista do Almirante) com as demais. A disponibilidade de fósforo é muito superior nesta, muito em função do estágio mais avançado da vegetação. Saynes et al (2005) observaram em florestas secas que o nitrogênio é em maior disponibilidade e o carbono não apresenta grandes diferenças, ao contrário do que foi observado neste estudo. A velocidade da recuperação dos nutrientes está diretamente relacionada ao tamanho e forma da clareira, assim como a sua disponibilidade.

Um dos aspectos mais interessantes observados é a questão do efeito de borda. Em todas as bordas houve diferença entre os valores dos nutrientes disponíveis em relação à área controle, principalmente em relação ao fósforo. Desta forma pode-se inferir que o desajuste na vegetação terá reflexos no solo, em função da importância da decomposição nestas áreas e das mudanças na composição da vegetação, com a substituição de espécies climácicas por espécies pioneiras. Assim os efeitos neste ecossistema das clareiras podem se propagar por até centenas de metros em direção a borda, caracterizando importantes vetores de transformação.

As clareiras transformam a paisagem da Mata Atlântica, criando um mosaico de estágios sucessionais e de habitats distintos, que podem levar a um aumento da biodiversidade na escala regional. Deanslow (1989) já havia destacado o papel de clareiras por queda de árvore na manutenção da biodiversidade, mas a escala em que os deslizamentos ocorrem é bem mais significativa na paisagem. Assim a dinâmica recorrente de deslizamentos associada à diversidade de habitats pode ser um importante condicionante da biodiversidade na Mata Atlântica. Hawkins et al (2003) já destacaram o papel que as condições de umidade e temperatura favoráveis estão relacionadas a diversidade, mas no caso é necessário associar este fator à dinâmica de perturbações, 
que são importantes na biodiversidade, como já foi destacado por Connell (1978) e Clark et al (2016), e a grande diversidade de habitats criados por estes eventos (Karr et al, 1973 e Ricklefs, 1977).

Os resultados de fauna corroboram o que foi visto até aqui em relação aos nutrientes do solo, mas cabe destacar que as relações entre os nutrientes do solo, mas que as relações não se dão por vias diretas, como já foi discutido em função das características desta fauna. A relação entre a fauna e a decomposição não correspondem ao encontrado por Hou et al (2005), que não observou diferenças significativas na decomposição associada a fauna de solo. É importante frisar que o trabalho trata de clareiras menores que as do presente estudo, e não considera o tamanho e a forma das mesmas. Henegahn et al (2004) também não encontraram diferenças tão marcantes na fauna em áreas sob 20 anos de sucessão como foi neste estudo. Já Wang et al (2009) encontrou forte associação entre a fauna e a decomposição, e consequentemente ciclagem, assim como é indicado neste estudo. Wehner at al (2014) observaram uma íntima relação entre a disponibilidade de recursos e a composição e densidade da fauna, e esta é importante para o controle e regulação da comunidade vegetal (Pizano et al, 2017).

Ainda existem diversas lacunas a serem preenchidas no quebra-cabeça que é a dinâmica de clareiras para o bioma de Mata Atlântica, mas pode-se observar a partir deste trabalho é que as clareiras são bem diferentes no tempo e no espaço, e as suas características morfológicas são importantes condicionantes para a sucessão. Quanto mais circular e maior a clareira, mais adversa a circunstância, e mais lenta a sucessão. Muitas vezes vistas apenas como perturbações ou desastres, na verdade os deslizamentos podem ter um importante papel na dinâmica da mata Atlântica, colaborando para a sua biodiversidade e a própria sustentabilidade deste ecossistema.

\section{REFERÊNCIAS:}

ALCANTARA-AYALA I.; ESTEBAN-CHÁVEZ O.; PARROT J. F.. Landsliding related to landcover change: A diachronic analysis of hillslope instability distribution in the Sierra Norte, Puebla, Mexico. Catena, n.65-1. Braunschweig: 2016 p 152 - 165.

BRANDÃO, A. M. P. M.. Análise climato-ambiental no município do Rio de Janeiro - Uma abordagem espaço-temporal com ênfase na década de 80. Rio de Janeiro. In: I Encontro Brasileiro de Ciências Ambientais, BNDES. 1994. p. 64-67. 
BROWN, S.; LUGO. A.. Effects of forest clearing and sucession on the carbon and nitrogen content of soils in Puerto Ricoand US Virgin Island. Plant and Soil, n.124. Netherlands: 1990. p. 54-64.

CAMPO J.; SOLIS E.; VALENCIA M. G.. Litter N and P dynamics in two secondary tropical dry forests after relaxation of nutrient availability constraints. Forest Ecology and Management. n.252. 2007. p. 33-40.

CASTRO Jr., E.. O papel da fauna endopedônica na estruturação física do solo e seu significado para a hidrologia de superfície. Tese de Mestrado, P.P.G. em Geografia/UFRJ, 1991. $150 \mathrm{p}$.

CHIROL, A.A.. Relações solo-fauna durante sucessão florestal em cictrizes de deslizamento; Dissertação de Mestrado, P.P.G. em Geografia/UFRJ, 2003. 148p.

CLARK , K. E.; WEST A.J.; HILTON R. G.; ASNER G. P. ; QUESADA C. A.; SILMAN M. R. , SAATCHI S. S. ; FARFAN-RIOS W.; MARTIN R. E. ; HORWATH A. B. ; HALLADAY K. ; NEW M. AND Y. MALHIY.. Storm-triggered landslides in the Peruvian Andes and implications for topography, carbon cycles, and biodiversity . Earth Surf. Dynam., n.4. 2016. p. 47-70.

COELHO NETTO, A.L. Overlandflow production in a Tropical rainforest Catchment: the role of litter cover. Catena, n.1, Braunschweig: 1987. p.213 231.

COELHO-NETTO A.L.; AVELAR A.S.; FERNANDES M.C..; LACERDA, W.A.. Landslide susceptibility in a mountainous geoecosystem, Tijuca Massif, Rio de Janeiro: The role of morphometric subdivision of the terrain. Geomorphology, n. 87-3, 2007. p. 120-131.

CONNELL, J. H.. Diversity in tropical rain forest and coral reefs. Science, n. 199, 1978, p. 13021310.

COSTA, N.M. da,. Geomorfologia estrutural dos Maciços litorâneos do Rio de Janeiro. Dissertação de Mestrado apresentado ao programa de pós graduação. em Geografia /UFRJ, 1986. $108 \mathrm{p}$. 
DE VUONO, Y.S.. Inventário fitossociológico. In SYLVESTRE LS; ROSA MMT(org) Manual metodológico para estudos botânicos na Mata Atlântica. EDUR, 2002. p. 51-65.

DENSLOW, J. S.. Tropical rain forest gaps and tree species diversity. Annual Review of Ecology and Systematics. n. 18, 1987. p. 431-451.

FERNANDES, N. F. ; GUIMARÃES, R. F. ; GOMES, R. A. T. ; VIEIRA, B. C. ; MONTGOMERY, D. R. ; GREENBERG, H. . Topographic Controls of Landslides in Rio de Janeiro: Field Evidences and Modeling. Catena, n. 55, Amsterdam: 2004. p. 163-181.

GALICIA L.; GARCIA-OLIVA, F. Remnant tree effects on soil microbial carbon and nitrogen in tropical seasonal pasture in western Mexico. European journal of soil Biology, n. 44, 2008. 290297.

GLADE, T.. Landslide occurrence as a response to land use change: a review of evidence from New Zealand. Catena, n. 51, 2003. p. 297- 314.

GEERTSEMA, M.; POJAR J. J.. Influence of landslides on biophysical diversity - A perspective from British Columbia. Geomorphology, n. 89-1, 2007. p. 55-69.

GUARIGUATA, M.. Landslide Disturbance And Forest Regeneration In The Upper Luquillo Mountains Of Puerto Rico. Journal of Ecology n. 78, 1990. p. 814-832.

GUARIGUA, M.R.; OSTERTAG, R.. Neotropical secondary forest succession: changes in structural and functional characteristics. Forest ecology and management, n. 148, 2001. P. 185206.

HENEGHAN, L.; SALMORE, A. D. A.; CROSSLEY, J. R. D.. A Recovery of decomposition and soil microarthropod communities in an Appalachian watershed two decades after a clearcut. Forest Ecology and Management. n.189, 2004. p. 353-362.

HAWKINS, B. A.; FIELD, R.; CORNELL, H. V.; CURRIE, D. J.; GUEGAN, J. F.; KAUFMAN, D. M.; KERR, J. T.; MITTELBACH, G. G.; OBERDORFF, T.; O`BRIEN, E. M., PORTER, E. E.; 
TURNER, J. R. G.. Energy, water, and broad scale geographic patterns of species richness. Ecology, n. 84, 2003. p. 3105-3117.

KARR, J. R.; ROTH, R. R.. Vegetation structure and avian diversity in several new World áreas. American nature. n. 105, 1971. p. 423-435

LARSEN, M. C., TORRES-SANCHEZ, A. J., CONCEPCION, I. M., Slopewash, surface runoff and fine litter transport in forest and landslide scars in humid-tropical steeplands, Luquillo Experimental Forest, Puerto Rico. Earth Surf. Process. And Landforms, n. 24, 1999. p. 481-502. LEE, K. E.; FOSTER R. C.. Soil fauna and soil structure. Australian Journal of Soil Resources, n. 29, 1992. P. 745-746.

LIN, W. T; CHOU, W. C; LIN, C. Y; HUANG, P. H; TSAI, J. S.. Vegetation recovery monitoring and assessment at landslides caused by earthquake in Central Taiwan. Forest Ecology and Management. n. 210, 2005. p. 55-66.

NEGREIROS, A. B.; COELHO NETTO, A. L.. Reabilitação Funcional De Clareira De Deslizamento Em Encosta Íngreme No Domínio Da Floresta Atlântica, Rio De Janeiro (RJ). Revista Brasileira de Geomorfologia, n. 10-1, 2009. p. 85-93.

NETO, C.; CARDigOS, P.; OLIVEIRA, S. C.; ZÊZERE, J. L.. Floristic and vegetation successional processes within landslides in a Mediterranean environment. Science of The Total Environment, Vol n. 574, 2017. P. 969-981.

OADE, J.M.. The role of biology in the formation, stabilization and degradation of soil structure. Geoderma, n. 56, Amsterdã: 1993, p. 377-400.

PIZANO, C.; MANGAN, S. A.; GRAHAM, J. H.; KITAJIMA, K.. Host-specific effects of soil microbial filtrates prevail over those of arbuscular mycorrhizae in a fragmented landscape. Ecological aplications, n. 27-6, 2017. p. 1946-1957.

RAJAGOPAL, D.; GANESHA BAT, U.. Distribution and abundance of different soil microarthropods communities in different soils, in: Structure and function of soil communities. Kyoto: Univ. Press, 1995. p. 34-41. 
RESTREPO, C.; PETER, V. P.; NEVILlE, P.. Landslides significantly alter land cover and the distribution of biomass: an example from the Ninole ridges of Hawaii. Plant Ecology, n. 166, Netherlands:2003. p. 131-143.

ROCHA LEÃO, O.M., Potencialidades e limitações da revegetação no controle da hidrologia e erosão de solos. Dissertação de Mestrado apresentado ao Programa De Pós Graduação Em Geografia da Universidade Federal do Rio de Janeiro, 1997. 142 pág.

SAYNES, V.; HIDAlGO, C.; ETCHEVERS, J. D.; CAMPO, J, E.. Soil C and N dynamics in primary and secondary seasonally dry tropical forests in Mexico. Applied Soil Ecology, n. 29, 2005. p. 282-289.

SCHALLER, F. Soil Animals. Univ. of Michigan Press, 138p. (1968)

SILVA FILHO, E.P. Movimentos de massa na vertente sul do Maciço da Tijuca,RJ: casos de fevereiro de 1988 nas estradas Dona Castorina e Vista Chinesa. P.P.G. em Geografia /UFRJ, 272 pág. (1992)

SWIFT, M.J.; HEAL, O W.; ANDERSON, J.M.; Decomposition in terrestrial ecosystems, University of California Press, Berkley and L.A. (1979)

Sylvain, Z.A; Wall, D.H.; Cherwin, K.L.; Peters, D.P.C.; Reichmann L.G.; Sala, O.E.; Soil animal responses to moisture availability are largely scale, not ecosystem dependent: insight from a cross-site study; Global Change Biology Vol 20, n*8, pág. 2631-2643(2014)

VILELLA. C L Comportamento erosivo de solos sob revegetação em cicatriz de movimento de massa. Dissertação (Mestrado em Geografia) PPGG/UFRJ 105 f. (2003)

WANG S; RUANGH; Wang B Effects of soil microarthropods on plant litter decomposition across an elevation gradient in the Wuyi Mountains Soil Biology \& Biochemistry 41 (2009) 891-897 
WEHNER, K.; SCHEU S.; MARAUN, M.; Resource Availability as Driving Factor of the Reproductive Mode in Soil Microarthropods (Acari, Oribatida) PLOS ONE 9(8): (2014)

ZARIN, D. J., JOHNSON, A.J, Nutrient Accumulation during primary succession in a Montane Tropical Forest, Puerto Rico, Soil Sci. Soc. Am. Journal, 59; pág. 1444$1452(1995)$

\section{AGRADECIMENTOS}

À Fundação de Amparo à Pesquisa do Rio de Janeiro, à EMBRAPA SOLOS, ao Programa de Pós-graduação em Geografia da Universidade Federal do Rio de Janeiro, ao CNPq e CAPES.

Recebido em: 15/08/2018

Aceite para publicação em: 05/11/2018 